\title{
Novel Acyl-CoA: Cholesterol Acyltransferase Inhibitor: Indoline-Based Sulfamide Derivatives with Low Lipophilicity and Protein Binding Ratio
}

\author{
Kenji Takahashi, Masaru Ohta, Yoshimichi Shoj, Masayasu Kasai, Kazuyoshi Kunishiro, \\ Tomohiro Mirke, Mamoru KandA, and Hiroaki ShIRAHASE* \\ Research Laboratories, Kyoto Pharmaceutical Industries, Ltd.; 38 Nishinokyo Tsukinowa-cho, Nakagyo-ku, Kyoto \\ 604-8444, Japan. Received April 8, 2010; accepted May 19, 2010
}

To find a novel acyl-CoA: cholesterol acyltransferase inhibitor, a series of sulfamide derivatives were synthesized and evaluated. Compound 1d, in which carboxymethyl moiety at the 5-position of Pactimibe was replaced by a sulfamoylamino group, showed 150 -fold more potent anti-foam cell formation activity $\left(\mathrm{IC}_{50}: 0.02 \mu \mathrm{M}\right)$, 1.6fold higher $\log D_{7.0}(4.63)$, and a slightly lower protein binding ratio $(93.2 \%)$ than Pactimibe. Compound $1 \mathrm{i}$, in which the octyl chain at the 1-position in $1 \mathrm{~d}$ was replaced by an ethoxyethyl, showed markedly $\operatorname{low} \log D_{7.0}(1.73)$ and maintained 3-fold higher anti-foam cell formation activity $\left(\mathrm{IC}_{50}: 1.0 \mu \mathrm{M}\right)$, than Pactimibe. The plasma protein binding ratio (PBR) of $1 \mathrm{i}$ was much lower than that of Pactimibe (62.5\% vs. $98.1 \%)$, and its partition ratio to the rabbit atherosclerotic aorta after oral administration was higher than that of Pactimibe. Compound 1i at $10 \mu_{\mathrm{M}}$ markedly inhibited cholesterol esterification in atherosclerotic rabbit aortas even when incubated with serum, while Pactimibe had little effect probably due to its high PBR. In conclusion, compound 1i is expected to more efficiently inhibit the progression of atherosclerosis than Pactimibe.

Key words acyl-CoA: cholesterol acyltransferase; sulfamide derivative; protein binding ratio; lipophilicity; foam cell formation; Pactimibe

Numerous acyl-CoA: cholesterol acyltransferase (ACAT) inhibitors have been reported as potential hypolipidemic drugs, which inhibit intestinal and hepatic esterification of cholesterol, ${ }^{1-5)}$ and anti-atherosclerotic drugs, which inhibit macrophage esterification of cholesterol in atherosclerotic plaques ${ }^{6}$; however, most of the reported inhibitors have been highly lipophilic and demonstrated to have low bioavailability. We previously synthesized a new indoline-based ACAT inhibitor, Pactimibe, with a carboxymethyl group at the 5-position, which was moderately lipophilic, highly water soluble, showed good oral absorption, and exerted excellent experimental anti-atherosclerotic effects. ${ }^{7)}$ Pactimibe decreased the atherosclerotic areas in apo-E knockout mice and stabilized aortic plaques in Watanabe heritable hyperlipidemic rabbits (WHHL rabbits) ${ }^{8,9}$; however, a clinical study using an intravascular-ultrasonography catheter (ACTIVATE study) failed to show plaque retardation at a dose of $100 \mathrm{mg}$ in patients with coronary artery disease (CAD) ${ }^{10)}$ It cannot be excluded that Pactimibe may have not fully inhibited plaque ACAT activity, since Pactimibe probably has a high plasma protein binding ratio (PBR), suggesting low partition to atherosclerotic plaques. A new less lipophilic ACAT inhibitor that has more potent biological effects and lower PBR would more efficiently inhibit plaque ACAT activity and would be a candidate for a new anti-atherosclerotic drug. In the case of Pactimibe, the introduction of a carboxymethyl group to its indoline ring resulted in an increase in its water solubility and bioavailability whilst maintaining its biological activity. In the present study, we replaced a carboxymethyl moiety of Pactimibe with a sulfamoylamino moiety, which markedly enhanced its anti-foam cell formation activity via ACAT inhibition and slightly increased its lipophilicity, as well as reducing its PBR. A series of sulfamide derivatives were synthesized and a compound with an ethoxyethyl group at the 1position was found to show much lower lipophilicity and $\mathrm{PBR}$, and more potent anti-foam cell formation (AFCF) activities than Pactimibe.
Chemistry Indoline-based sulfamide derivatives with no substituents at the 2-position of the indoline ring $(\mathbf{1} \mathbf{a}-\mathbf{k})$ were synthesized from $N$-(1-acetyl-4,6-dimethylindolin-7-

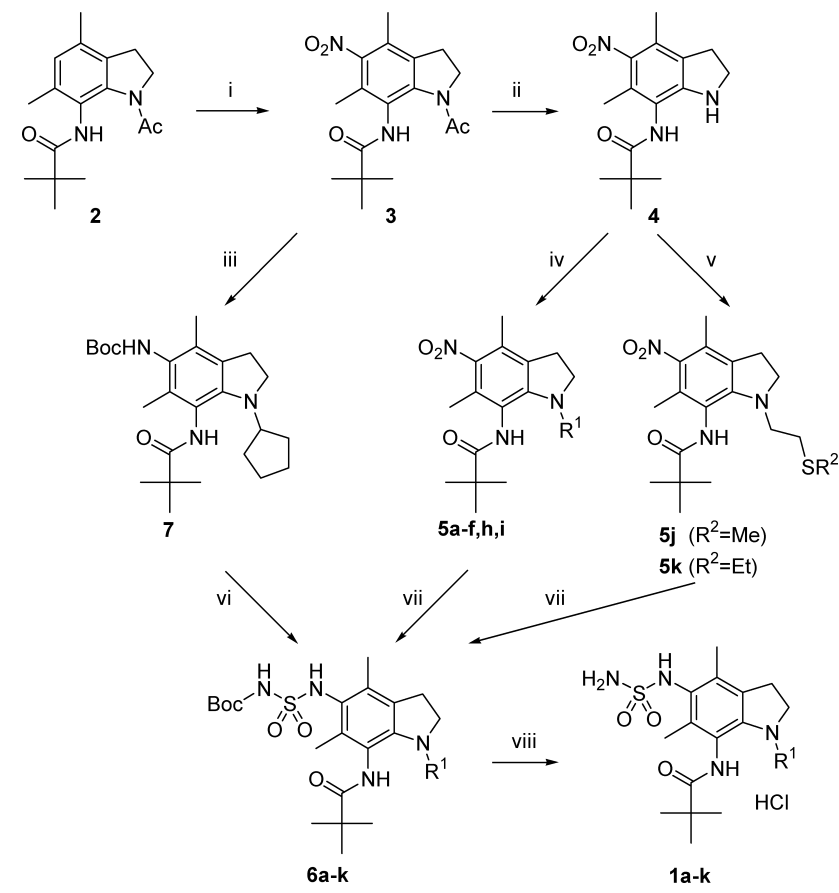

Reagents, conditions and yields: (i) fum. $\mathrm{HNO}_{3}$, conc. $\mathrm{H}_{2} \mathrm{SO}, \mathrm{AcOH}, 10^{\circ} \mathrm{C}$; (ii) $\mathrm{NaOH}$ solution, $\mathrm{MeOH}$, reflux, 2 steps $94 \%$; (iii) (a) $\mathrm{H}_{2}, \mathrm{Pd}-\mathrm{C}$, rt, $93 \%$; (b) $\mathrm{Boc}_{2} \mathrm{O}, \mathrm{Et}_{3} \mathrm{~N}, 90^{\circ} \mathrm{C}, 37 \%$; (c) $\mathrm{NaOH}$ solution, $\mathrm{EtOH}$, reflux, $68 \%$; (d) cyclopentyl bromide, $i$ - $\mathrm{Pr}_{2} \mathrm{NEt}$, KI, hydroquinone, DMF, $90^{\circ} \mathrm{C}, 21 \%$; (iv) alkyl halide, $\mathrm{NaH}$, DMF, $0{ }^{\circ} \mathrm{C}-\mathrm{rt}$ or alkoxyethyl halide, $i$-Pr ${ }_{2} \mathrm{NEt}$, DMF, $110^{\circ} \mathrm{C}, 32-80 \%$; (v) (a) 2 bromoethanol, $i-\mathrm{Pr}_{2} \mathrm{NEt}, \mathrm{DMF}, 120^{\circ} \mathrm{C}, 67 \%$; (b) $\mathrm{MsCl}_{1} \mathrm{Et}_{3} \mathrm{~N}, \mathrm{CHCl}_{3}, 0^{\circ} \mathrm{C}$; (c) AcSK, DMF, $70^{\circ} \mathrm{C}$; (d) $\mathrm{NaOH}$ solution, $\mathrm{MeOH}, 0{ }^{\circ} \mathrm{C}, 3$ steps $85 \%$; (e) MeI (for 5j) or EtI (for $\mathbf{5 k}$ ), $i-\mathrm{Pr}_{2} \mathrm{NEt}, \mathrm{DMF}, \mathrm{rt}, 91$ or $86 \%$, respectively; (vi) (a) $\mathrm{HCl}$ in $i$ $\mathrm{PrOH}, \mathrm{HCO}_{2} \mathrm{H}, 0^{\circ} \mathrm{C}$; (b) BocNHSO $\mathrm{Cl}_{2}$ (prepared from tert-BuOH and chlorosulfonyl isocyanate), $\mathrm{Et}_{3} \mathrm{~N}, \mathrm{CH}_{2} \mathrm{Cl}_{2},-10^{\circ} \mathrm{C}, 2$ steps $69 \%$; (vii) (a) $\mathrm{H}_{2}, \mathrm{Pd}-\mathrm{C}, \mathrm{MeOH}$, $35^{\circ} \mathrm{C}$; (b) $\mathrm{BocNHSO}_{2} \mathrm{Cl}, \mathrm{Et}_{3} \mathrm{~N}, \mathrm{CH}_{2} \mathrm{Cl}_{2},-10^{\circ} \mathrm{C}, 2$ steps $36-77 \%$; (viii) $\mathrm{HCl}$ in $i$ $\mathrm{PrOH}, \mathrm{HCO}_{2} \mathrm{H}, 0{ }^{\circ} \mathrm{C}, 52-94 \%$

Chart 1. Synthesis of Indoline-Based Sulfamide Derivatives with No Substitution at the 2-Position 
yl)-2,2-dimethylpropanamide (2) as outlined in Chart 1. Compound 2 was synthesized from 1-acetyl-4,6-dimethylindoline according to the method previously reported ${ }^{11)}$ and then nitrated to give compound 3 with a nitro group at the 5position. To prepare $\mathbf{1 a}-\mathbf{f}, \mathbf{h}-\mathbf{k}$, compound $\mathbf{3}$ was hydrolyzed to give compound 4 with no substituents at the 1position, and then various chains, e.g. straight alkyl, branched alkyl, and ether chains, were introduced to 4 at the 1-position using $i$ - $\mathrm{Pr}_{2} \mathrm{NEt}$ or $\mathrm{NaH}$ as a base to give $\mathbf{5 a}-\mathbf{f}, \mathbf{h}$, i. Separately, compound $\mathbf{4}$ was alkylated with 2-bromoethanol at the 1-position, followed by mesylation, and then the mesylate compound was converted to thioether derivatives $\mathbf{5 j}, \mathbf{k}$. The nitro moiety of compounds $\mathbf{5 a}-\mathbf{f}$, $\mathbf{h}$ - $\mathbf{k}$ was hydrogenated, followed by the reaction with Boc$\mathrm{NHSO}_{2} \mathrm{Cl}$, which was previously generated by the reaction of chlorosulfonyl isocyanate with tert- $\mathrm{BuOH}$, to give $\mathbf{6 a}-\mathbf{f}$, $\mathbf{h}$ - $\mathbf{k}$ with Boc-protected sulfamoylamino moiety at the 5position. To prepare compound $\mathbf{6 g}$ with a cyclopentyl moiety at the 1-position, the nitro moiety of $\mathbf{3}$ was converted to Bocprotected amino moiety. The acetyl moiety was hydrolyzed, and then a cyclopentyl moiety was introduced to give compound 7. The Boc group of 7 was cleaved by treating with $\mathrm{HCl}$, followed by conversion to $\mathbf{6 g}$ according to the method described above. Finally, the Boc group of $\mathbf{6} \mathbf{a}-\mathbf{k}$ was deprotected with $\mathrm{HCl}$ to obtain compounds $\mathbf{1 a -}-\mathbf{k}$ as a hydrochloride salt.

Indoline-based sulfamide derivatives with a methyl or butyl moiety at the 2-position $(\mathbf{9 a}-\mathbf{d})$ were prepared as outlined in Chart 2. 3,5-Dimethylphenylhydrazine (10) was converted to 2,4,6-trimethylindole (11) by Fisher indole synthesis. Compound $\mathbf{1 1}$ was reduced by $\mathrm{NaBH}_{3} \mathrm{CN}$ and acetylated

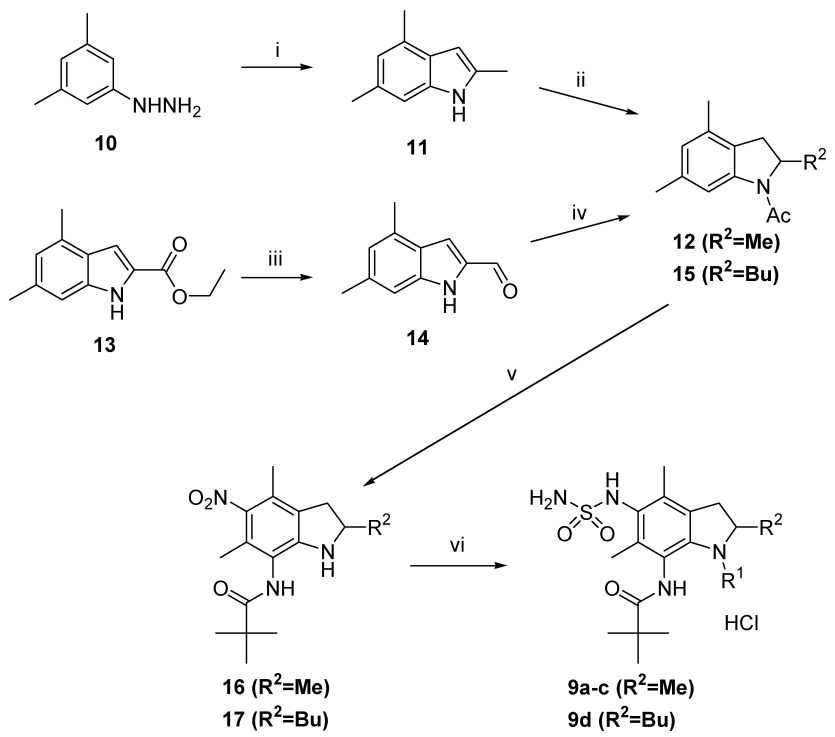

Reagents, conditions and yields: (i) acetone, PPA, $140{ }^{\circ} \mathrm{C}, 80 \%$; (ii) (a) $\mathrm{NaBH}_{3} \mathrm{CN}, \mathrm{AcOH}, 0{ }^{\circ} \mathrm{C}$; (b) $\mathrm{Ac}_{2} \mathrm{O}$, benzene, rt, 2 steps $85 \%$; (iii) (a) $\mathrm{LiAlH}_{4}$, $\mathrm{Et}_{2} \mathrm{O}$, rt; (b) $\mathrm{MnO}_{2}, \mathrm{CH}_{2} \mathrm{Cl}_{2}$, rt, 2 steps $62 \%$; (iv) (a) allyltriphenylphosphonium bromide, $n$-BuLi, THF, $10{ }^{\circ} \mathrm{C}$; (b) $\mathrm{H}_{2}, \mathrm{Pd}-\mathrm{C}$, $\mathrm{MeOH}, 35^{\circ} \mathrm{C}$; (c) $\mathrm{NaBH}_{3} \mathrm{CN}, \mathrm{AcOH}$, $10^{\circ} \mathrm{C}$; (d) $\mathrm{Ac}_{2} \mathrm{O}, \mathrm{CHCl}_{3}, \mathrm{Et}_{3} \mathrm{~N}$, rt, 4 steps $42 \%$; (v) (a) $\mathrm{Br}_{2}, \mathrm{AcOH}, \mathrm{rt}, 94-100 \%$; (b) fum. $\mathrm{HNO}_{3}$, conc. $\mathrm{H}_{2} \mathrm{SO}_{4}, \mathrm{AcOH},-10{ }^{\circ} \mathrm{C}, 70-100 \%$; (c) $\mathrm{H}_{2}, \mathrm{Pd}-\mathrm{C}, \mathrm{MeOH}$, $40^{\circ} \mathrm{C}$; (d) pivaloyl chloride, $\mathrm{Et}_{3} \mathrm{~N}, \mathrm{CH}_{2} \mathrm{Cl}_{2}, 0{ }^{\circ} \mathrm{C}, 2$ steps $72-100 \%$; (e) fum. $\mathrm{HNO}_{3}$, conc. $\mathrm{H}_{2} \mathrm{SO}_{4}, \mathrm{AcOH}, 0{ }^{\circ} \mathrm{C}, 72-84 \%$; (f) $\mathrm{NaOH}$ solution, $\mathrm{EtOH}, 60{ }^{\circ} \mathrm{C}$, 97-98\%; (vi) (a) alkyl halide, $i$-Pr ${ }_{2} \mathrm{NEt}, \mathrm{DMF}, 110^{\circ} \mathrm{C}$, or MeI, $\mathrm{NaH}, \mathrm{DMF}$, rt, 52-89\%; (b) $\mathrm{H}_{2}, \mathrm{Pd}-\mathrm{C}, \mathrm{MeOH}, 35^{\circ} \mathrm{C}$; (c) BocNHSO ${ }_{2} \mathrm{Cl}, \mathrm{Et}_{3} \mathrm{~N}, \mathrm{CH}_{2} \mathrm{Cl}_{2},-10^{\circ} \mathrm{C}$, 2 steps $61-89 \%$; (d) $\mathrm{HCl}$ in $i$ - $\mathrm{PrOH}, \mathrm{HCO}_{2} \mathrm{H}, 0^{\circ} \mathrm{C}, 62-67 \%$.

Chart 2. Synthesis of Indoline-Based Sulfamide Derivatives with Methyl or Butyl Moiety at the 2-Position at the 1-position to give compound 12. Separately, the ester function of ethyl 4,6-dimethylindole-2-carboxylate $(\mathbf{1 3})^{12}$ ) was reduced with $\mathrm{LiAlH}_{4}$, followed by successive oxidation with activated $\mathrm{MnO}_{2}$ to afford an aldehyde derivative 14 . Then, compound $\mathbf{1 4}$ was converted to $\mathbf{1 5}$ with a butyl moiety at the 2-position by the Wittig reaction and successive hydrogenation, followed by reduction of the indole ring. Compounds 12 and 15 were converted to 1,2-disubstituted indolines $\mathbf{9 a}-\mathbf{d}$ via deacetylated compounds $\mathbf{1 6}$ and $\mathbf{1 7}$ according to the method described in Chart 1.

Indoline-based sulfamide derivatives with ether or thioether moiety at the 2-position (18a-d) were synthesized as outlined in Chart 3. An ester compound $\mathbf{1 3}$ was reduced with $\mathrm{LiAlH}_{4}$ and $\mathrm{NaBH}_{3} \mathrm{CN}$, and then acetylated to give compound 19. Compound 19 was selectively deacetylated at the 2-position, and then alkylated with MeI and EtI to give 20 and 21, respectively. Compounds $\mathbf{2 0}$ and $\mathbf{2 1}$ were converted to $\mathbf{1 8 a}, \mathbf{b}$ via 5 -nitroindoline derivatives $\mathbf{2 2 a}, \mathbf{b}$ as described in Chart 1. Separately, compound $\mathbf{1 9}$ was converted to $\mathbf{2 3}$ with a hydroxymethyl moiety at the 2-position as described in Chart 1, and then the hydroxymethyl moiety was converted to the thioether moiety to give $22 \mathbf{c}, \mathbf{d}$, followed by conversion to compounds $\mathbf{1 8 c}, \mathbf{d}$.

An indoline-based sulfamide derivative with a methoxyethyl moiety at the 3-position (24) was synthesized as outlined in Chart 4. 4,6-Dimethylindole (25) was reacted with oxalyl chloride, and successively esterified to give a product with ethyl oxalate at the 3-position, which was reduced with $\mathrm{LiAlH}_{4}$ and $\mathrm{NaBH}_{3} \mathrm{CN}$, and protected with Boc group to obtain a compound with a hydroxyethyl moiety at the 3-position. Then, the compound was methylated at the hydroxyl group, followed by exchanging Boc for an acetyl

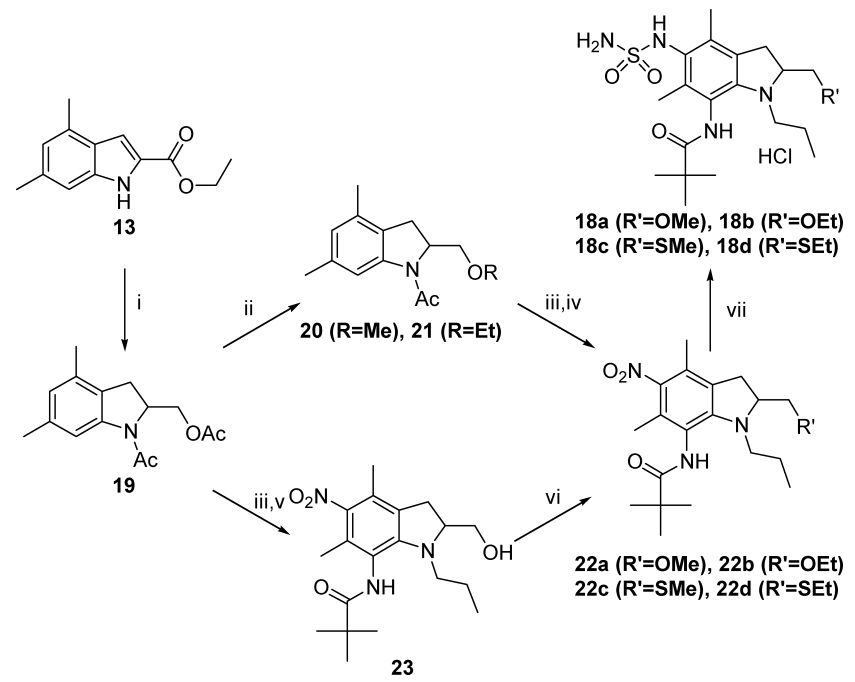

Reagents, conditions and yields: (i) (a) $\mathrm{LiAlH}_{4}, \mathrm{Et}_{2} \mathrm{O}$, rt; (b) $\mathrm{NaBH}_{3} \mathrm{CN}, \mathrm{AcOH}$, $10{ }^{\circ} \mathrm{C}$; (c) $\mathrm{Ac}_{2} \mathrm{O}, \mathrm{Et}_{3} \mathrm{~N}, \mathrm{CHCl}_{3}$, rt, 3 steps $77 \%$; (ii) (a) $\mathrm{LiOH}$ solution, $\mathrm{MeOH}$ $0^{\circ} \mathrm{C}, 96 \%$; (b) MeI (for 20) or EtI (for 21), NaH, DMF, 45 or $41 \%$, respectively; (iii) (a) $\mathrm{Br}_{2}, \mathrm{CHCl}_{3}, 0^{\circ} \mathrm{C}, 93-99 \%$; (b) fum. $\mathrm{HNO}_{3}$, conc. $\mathrm{H}_{2} \mathrm{SO}_{4}, \mathrm{AcOH}, 10-$ $15^{\circ} \mathrm{C}, 95-99 \%$; (c) $\mathrm{H}_{2}, \mathrm{Pd}-\mathrm{C}, \mathrm{MeOH}, 35^{\circ} \mathrm{C}$; (d) pivaloyl chloride, $\mathrm{Et}_{3} \mathrm{~N}, \mathrm{CH}_{2} \mathrm{Cl}_{2}$, $0{ }^{\circ} \mathrm{C}, 2$ steps $83-95 \%$; (e) fum. $\mathrm{HNO}_{3}$, conc. $\mathrm{H}_{2} \mathrm{SO}_{4}, \mathrm{AcOH}, 10^{\circ} \mathrm{C}, 92 \%$; (iv) (a) LiOH solution, $\mathrm{MeOH}, 0^{\circ} \mathrm{C}, 91 \%$; (b) $\mathrm{PrI}, i-\mathrm{Pr}_{2} \mathrm{NEt}, \mathrm{DMF}, 110^{\circ} \mathrm{C}, 61 \%$; (v) (a) $\mathrm{NaOH}$ solution, EtOH, reflux, $88 \%$; (b) $\mathrm{PrI}, i$ - $\mathrm{Pr}_{2} \mathrm{NEt}$, DMF, $100^{\circ} \mathrm{C}, 91 \%$; (vi) (a) $\mathrm{MsCl}, \mathrm{Et}_{3} \mathrm{~N}, \mathrm{CHCl}_{3}, 0{ }^{\circ} \mathrm{C}, 41 \%$; (b) AcSK, DMF, $70{ }^{\circ} \mathrm{C}, 80 \%$; (c) $\mathrm{NaOH}$ solution, $\mathrm{MeOH}, 0^{\circ} \mathrm{C}, 92 \%$; (d) $\mathrm{MeI}$ (for 22c) or EtI (for 22d), $i$-Pr ${ }_{2} \mathrm{NEt}, \mathrm{DMF}, \mathrm{rt}, 93 \%$; (vii) (a) $\mathrm{H}_{2}, \mathrm{Pd}-\mathrm{C}, \mathrm{MeOH}, \mathrm{rt}, 82 \%$; (b) $\mathrm{BocNHSO}_{2} \mathrm{Cl}, \mathrm{Et}_{3} \mathrm{~N}, \mathrm{CH}_{2} \mathrm{Cl}_{2},-10{ }^{\circ} \mathrm{C}$, $72-78 \%$; (c) $\mathrm{HCl}$ in $i$-PrOH, $\mathrm{HCO}_{2} \mathrm{H}, 0^{\circ} \mathrm{C}, 67-75 \%$.

Chart 3. Synthesis of Indoline-Based Sulfamide Derivatives with Ether or Thioether Moiety at the 2-Position 


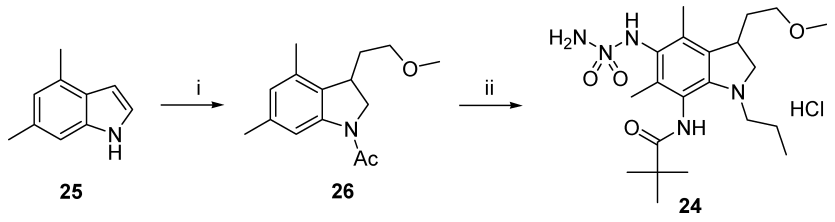

Reagents, conditions and yields: (i) (a) oxalyl chloride, $\mathrm{Et}_{2} \mathrm{O}$, rt; (b) EtOH, rt, 2 steps $54 \%$; (c) $\mathrm{LiAlH}_{4}$, THF, reflux, $100 \%$. (d) $\mathrm{NaBH}_{3} \mathrm{CN}, \mathrm{AcOH}, 10^{\circ} \mathrm{C}, 98 \%$; (e) $\mathrm{Boc}_{2} \mathrm{O}, \mathrm{THF}, \mathrm{rt}, 89 \%$; (f) MeI, NaH, DMF, rt; (g) $\mathrm{HCl}$ in $i$-PrOH, $\mathrm{HCO}_{2} \mathrm{H}, 0^{\circ} \mathrm{C}, 2$ steps $97 \%$; (h) $\mathrm{Ac}_{2} \mathrm{O}, \mathrm{Et}_{3} \mathrm{~N}, \mathrm{CHCl}_{3}, \mathrm{rt}, 100 \%$; (ii) (a) $\mathrm{Br}_{2}, \mathrm{CHCl}_{3}, \mathrm{rt}$; (b) fum $\mathrm{HNO}_{3}$, conc. $\mathrm{H}_{2} \mathrm{SO}_{4}, \mathrm{AcOH}, 10{ }^{\circ} \mathrm{C}, 2$ steps $66 \%$; (c) $\mathrm{H}_{2}, \mathrm{Pd}-\mathrm{C}, \mathrm{MeOH}, 35^{\circ} \mathrm{C}$; (d) pivaloyl chloride, $\mathrm{Et}_{3} \mathrm{~N}, \mathrm{CH}_{2} \mathrm{Cl}_{2}, 0^{\circ} \mathrm{C}, 2$ steps $100 \%$; (e) fum. $\mathrm{HNO}_{3}$, conc. $\mathrm{H}_{2} \mathrm{SO}_{4}$, $\mathrm{AcOH}, 10^{\circ} \mathrm{C}, 100 \%$; (f) $\mathrm{NaOH}$ solution, $\mathrm{MeOH}$, reflux, $74 \%$; (g) PrI, $\mathrm{NaH}, \mathrm{DMF}$ $0{ }^{\circ} \mathrm{C}, 86 \%$; (h) $\mathrm{H}_{2}, \mathrm{Pd}-\mathrm{C}, \mathrm{MeOH}, 35^{\circ} \mathrm{C}$; (i) $\mathrm{BocNHSO}_{2} \mathrm{Cl}, \mathrm{Et}_{3} \mathrm{~N}, \mathrm{CH}_{2} \mathrm{Cl}_{2},-10{ }^{\circ} \mathrm{C}$, 2 steps $92 \%$; (j) $\mathrm{HCl}$ in $i$ - $\mathrm{PrOH}, \mathrm{HCO}_{2} \mathrm{H}, 0{ }^{\circ} \mathrm{C}, 72 \%$.

Chart 4. Synthesis of Indoline-Based Sulfamide Derivative 24

group to give a 3-methoxyethyl indoline derivative 26, which was then converted to $\mathbf{2 4}$ in a similar manner to that described in Chart 1. Compound 27 (Pactimibe) with a carboxymethyl moiety, and compounds 28 (KY-455) and 29 with no substituents at the 5-position were synthesized according to the methods previously reported..$^{7,11}$

\section{Results and Discussion}

We have reported the synthesis and biological activities of Pactimibe, an indoline-based ACAT inhibitor with a carboxymethyl group at the 5-position. ${ }^{7)}$ Pactimibe exerted inhibitory effects on macrophage ACAT activities and was efficiently absorbed orally, suggesting that it would have potent anti-atherosclerotic effects; however, clinical studies failed to show a plaque-reducing effect in CAD patients. ${ }^{10)}$ It remains to be determined whether Pactimibe is unable to retard atherosclerosis due to insufficient ACAT inhibition and/or whether ACAT inhibition itself is ineffective at reducing human atherosclerotic plaques. Pactimibe showed high water solubility and bioavailability whilst maintaining high ACAT inhibitory activity, while its PBR was high because it is a relatively large lipophilic molecule with an ionizable moiety. The high PBR may have resulted in low partition into atherosclerotic plaques in some patients. Thus, we attempted to introduce a sulfamoylamino group instead of the carboxyl moiety at the 5-position, which is unionized around neutral $\mathrm{pH}$, to find a new bioavailable inhibitor with low lipophilicity and PBR. Lipophilicity $\left(\log D_{7.0}\right)$, rabbit PBR and inhibitory activity against foam cell formation of the sulfamide derivatives and related compounds were determined (Table 1). Compound 1d with a sulfamoylamino group at the 5-position and an octyl chain at the 1-position showed lower $\log D_{7.0}$ (4.63) than 29 (5.10), which had no substituent at the 5-position, ${ }^{11)}$ and higher $\log D_{7.0}$ than Pactimibe (2.85), which had a carboxymethyl moiety, while compound 1d showed lower PBR than 29 and Pactimibe (93.2, 99.2, 98.1\%, respectively). On the other hand, the AFCF activity of $\mathbf{1 d}\left(\mathrm{IC}_{50}: 0.02 \mu \mathrm{M}\right)$ was about 6-fold and 150-fold higher than those of $29\left(\mathrm{IC}_{50}\right.$ : $0.11 \mu \mathrm{M})$ and Pactimibe $\left(\mathrm{IC}_{50}: 3.0 \mu \mathrm{M}\right)$, respectively, indicating that introduction of a sulfamoylamino group is useful for increasing activity. To find a new well-balanced compound for lipophilicity, PBR and AFCF activity, various alkyl chains were introduced at the 1-, 2- and 3-positions of the indoline ring. Shortening the alkyl chain at the 1-position from octyl (1d) to pentyl (1c), butyl (1b) and propyl (1a) decreased $\log D_{7.0}, \mathrm{PBR}$, and $\mathrm{AFCF}$ activity. Compound 1a showed much lower $\log D_{7.0}$ and PBR $(2.03,72.5 \%$, respectively) than Pactimibe, while it still had about 3-fold more potent $\mathrm{AFCF}$ activity $\left(\mathrm{IC}_{50}: 0.95 \mu \mathrm{M}\right)$ than Pactimibe. Compound 1c with a pentyl chain showed much $\operatorname{lower} \log D_{7.0}$ (2.87) and PBR (80.1\%), and 30-fold stronger activity $\left(\mathrm{IC}_{50}\right.$ : $0.094 \mu \mathrm{M})$ than the corresponding compound 28 (KY-455) with no substituents at the 5-position. ${ }^{11,13)}$ All sulfamide derivatives prepared, except for 24, showed lower PBR and stronger AFCF activities than Pactimibe. Interestingly, 1b and 9a, and 1c and 9d showed similar AFCF activities, respectively, suggesting that a relatively small lipophilic chain at the 1- or 2-position is enough to interact with ACAT protein in sulfamide derivatives. Overall, AFCF activity and PBR increased in dependence on lipophilicity $\left(\log D_{7.0}\right)$ in the sulfamide derivatives synthesized: there were significant co-relationships between $\log \left(\mathrm{AFCF} \quad \mathrm{IC}_{50}\right)$ and $\log D_{7.0}$ $\left(r^{2}=0.777\right)$, between PBR and $\log D_{7.0}\left(r^{2}=0.763\right)$, and between $\log \left(\mathrm{AFCF} \mathrm{IC}_{50}\right)$ and PBR $\left(r^{2}=0.831\right)$, respectively. Sulfamide derivatives were demonstrated to maintain potent AFCF activities at much $\operatorname{lower} \log D_{7.0}$ and PBR than Pactimibe and KY-455 derivatives (28, 29). Low lipophilic sulfamide derivatives may have interacted with an ACAT protein in a manner different from those of high lipophilic inhibitors. Furthermore, in macrophages, the sulfamide derivatives may have efficiently reached the enzyme without being trapped by culture medium proteins, cell membrane, intracellular lipid and/or proteins. In particular, compounds $\mathbf{1 h}, \mathbf{1 i}$ and $9 \mathbf{b}$ with an alkoxy chain showed $\log D_{7.0}$ lower than 2.0 and PBR around $60 \%$. Among these, $1 \mathbf{i}$ with the most potent AFCF activity was selected for further evaluation.

Compound 1i potently inhibited hepatic ACAT activity $\left(\mathrm{IC}_{50}: 0.21 \mu \mathrm{M}\right)$, suggesting that it would exert hypolipidemic effects by inhibiting hepatic very low density lipoprotein (VLDL) secretion. Compound 1i showed good oral absorption in rats, rabbits, and dogs (Table 2). The maximal plasma concentration of $\mathbf{1 i}$ was higher than its $\mathrm{IC}_{50}$ values for AFCF and hepatic ACAT inhibitory activities. Unlike Pactimibe, compound 1i showed very low PBR; thus, the plasma concentration of the unbound form available for partition to the target organ was considered to be much higher than that of Pactimibe. Indeed, the partition ratio of Pactimibe from plasma to the atherosclerotic aorta was significantly lower than that of 1i: $0.10 \pm 0.03$ vs. $0.85 \pm 0.10(n=3, p<0.01$, Student's $t$-test). Furthermore, the anti-foam cell formation activity of $1 \mathbf{i}$ at $10 \mu \mathrm{M}$ was not affected by $5 \%$ albumin (\% inhibition; $65.7 \pm 9.9$ vs. $60.5 \pm 5.4, n=3$ ), while that of Pactimibe was markedly reduced (\% inhibition; $74.5 \pm 11.5$ vs. $33.1 \pm 6.2, n=3)$. Compound $\mathbf{1 i}$ at $10 \mu \mathrm{M}$ markedly inhibited the cholesterol esterification in isolated atherosclerotic aortas of Kurosawa and Kusanagi hypercholesterolemic (KHC) rabbits incubated with serum (\% inhibition; 70.8 \pm 3.6 ), while Pactimibe had little effect, probably due to its high PBR.

In conclusion, an indoline structure with a sulfamoylamino moiety is a useful scaffold to design a potent ACAT inhibitor with low lipophilicity and PBR. Compound $\mathbf{1 i}$ showed lower lipophilicity and PBR, and maintained higher inhibitory activity against cholesterol esterification in macrophages and atherosclerotic aorta than Pactimibe, even in the presence of albumin or serum, probably due to its lower PBR. In addition, it also inhibited hepatic ACAT activity. Compound 1i would more potently and consistently prevent atherosclerotic 
Table 1. Chemical Structures, Molecular Weights, $\log D_{7.0}$, Inhibitory Activity against Foam Cell Formation (AFCF), and Plasma Protein Binding Ratio (PBR) of Indoline-Based Sulfamide Derivatives

\begin{tabular}{|c|c|c|c|c|c|c|c|}
\hline Structure & Compound & $\mathrm{R}^{1}$ & $\mathrm{R}^{2}$ & $\begin{array}{l}\text { M.W. } \\
\text { (free) }\end{array}$ & $\log D_{7.0}$ & $\begin{array}{c}\mathrm{AFCF}^{a)} \\
\left(\mathrm{IC}_{50}, \mu \mathrm{M}\right)\end{array}$ & $\begin{array}{l}\mathrm{PBR}^{b)} \\
(\%)\end{array}$ \\
\hline & $1 \mathrm{a}$ & & $-\mathrm{H}$ & 382.52 & 2.03 & 0.95 & 72.5 \\
\hline & $1 b$ & & $-\mathrm{H}$ & 396.55 & 2.45 & 0.44 & 70.5 \\
\hline & $1 c$ & & $-\mathrm{H}$ & 410.58 & 2.87 & 0.094 & 80.1 \\
\hline & 1d & & $-\mathrm{H}$ & 452.65 & 4.63 & 0.02 & 93.2 \\
\hline & $1 \mathrm{e}$ & & $-\mathrm{H}$ & 396.55 & 2.52 & 0.30 & 72.3 \\
\hline & 1f & & $-\mathrm{H}$ & 410.58 & 2.93 & 0.17 & 85.6 \\
\hline & $1 g$ & & $-\mathrm{H}$ & 408.56 & 2.42 & 0.62 & 69.8 \\
\hline & 1h & & $-\mathrm{H}$ & 398.52 & 1.40 & 2.7 & 58.6 \\
\hline & $1 \mathrm{i}$ & & $-\mathrm{H}$ & 412.55 & 1.73 & 1.0 & 62.5 \\
\hline & $1 \mathrm{j}$ & & $-\mathrm{H}$ & 414.59 & 1.88 & 0.96 & 68.2 \\
\hline & $1 \mathrm{k}$ & & $-\mathrm{H}$ & 428.61 & 2.29 & 0.33 & 70.3 \\
\hline & $9 a$ & & $-\mathrm{CH}_{3}$ & 396.55 & 2.45 & 0.54 & 72.5 \\
\hline & $9 b$ & & $-\mathrm{CH}_{3}$ & 412.55 & 1.84 & 1.8 & 58.2 \\
\hline & $9 c$ & & $-\mathrm{CH}_{3}$ & 426.57 & 2.25 & 0.63 & 66.3 \\
\hline & $18 \mathrm{a}$ & & ใด & 426.57 & 2.22 & 0.44 & 71.9 \\
\hline & $18 \mathrm{~b}$ & & ใิ & 440.60 & 2.61 & 0.15 & 73.9 \\
\hline & $18 \mathrm{c}$ & & & 442.64 & 2.71 & 0.21 & 73.6 \\
\hline & $18 d$ & & & 456.67 & 3.14 & 0.036 & 80.3 \\
\hline & 9d & & $\xi \smile$ & 396.55 & 3.02 & 0.056 & 82.3 \\
\hline & 24 & & & 440.60 & 2.34 & 4.0 & 63.2 \\
\hline & $\begin{array}{c}27 \\
\text { (Pactimibe) }\end{array}$ & & & 416.60 & 2.85 & 3.0 & 98.1 \\
\hline & $\begin{array}{c}28 \\
(\mathrm{KY}-455)\end{array}$ & & & 316.48 & 3.67 & 3.0 & 99.6 \\
\hline & 29 & & & 358.56 & 5.10 & 0.11 & 99.2 \\
\hline
\end{tabular}

a) Inhibitory activity against foam cell formation in THP-1 cells, $n=2$. b) Mean of duplicate assay. 
Table 2. Maximal Plasma Concentrations of Compound $\mathbf{1 i}$ and Pactimibe after Oral Administration at $10 \mathrm{mg} / \mathrm{kg}$ in Male Rats, Rabbits, and Dogs

\begin{tabular}{lccc}
\hline \hline & Rat & Rabbit & Dog \\
\hline & & $C_{\max }(\mu \mathrm{g} / \mathrm{ml})$ & \\
\cline { 2 - 3 } & & $1.3 \pm 0.48$ & 4.9 \\
$\mathbf{1 i}$ & $0.72 \pm 0.07$ & $3.0 \pm 1.50$ & 7.3
\end{tabular}

Mean \pm S.E. $(n=2-3)$.

plaque formation and promote its regression than Pactimibe.

\section{Experimental}

General Procedures Chemicals were obtained from commercial sources and used without purification. Reactions were monitored by TLC on Merck precoated silica gel $60 \mathrm{~F}_{254}(0.25 \mathrm{~mm})$ plates. Column chromatography was performed on silica gel (Daisogel No. 1001W; Daiso, Osaka, Japan). Melting points were measured on a melting point apparatus (MP500P; Yanaco, Kyoto, Japan) and are uncorrected. IR spectra were obtained with an infrared spectrometer (FT-IR 8200PC; Shimadzu, Kyoto, Japan). ${ }^{1} \mathrm{H}-$ NMR spectra were recorded on a nuclear magnetic resonance spectrometer at $400 \mathrm{MHz}$ (JNM-AL400; JEOL, Tokyo, Japan) or $90 \mathrm{MHz}$ (R-1900; Hitachi, Tokyo) using tetramethylsilane as an internal standard. MS spectra were obtained on a QTRAP LC/MS/MS system (API2000, Applied Biosystems; Foster, CA, U.S.A.).

Procedure for the Synthesis of 1i Compound 1i was synthesized from $\mathbf{2}$ via $\mathbf{3}, \mathbf{4}, \mathbf{5 i}$, and $\mathbf{6} \mathbf{i}$ as follows:

$\mathrm{N}$-(1-Acetyl-4,6-dimethyl-5-nitroindolin-7-yl)-2,2-dimethylpropanamide (3): To a solution of $2(1.99 \mathrm{~g}, 6.90 \mathrm{mmol})$ in $\mathrm{AcOH}(20 \mathrm{ml})$ in an ice bath was added fuming $\mathrm{HNO}_{3}(0.41 \mathrm{ml}, 10 \mathrm{mmol})$. The reaction mixture was stirred at room temperature overnight and at $50{ }^{\circ} \mathrm{C}$ for $4 \mathrm{~h}$. After the mixture was poured into water, the precipitate formed was collected by filtration. A solution of the collected material in $\mathrm{CHCl}_{3}(300 \mathrm{ml})$ was washed with saturated $\mathrm{NaHCO}_{3}$ solution and brine, dried over $\mathrm{Na}_{2} \mathrm{SO}_{4}$, and then evaporated under reduced pressure. The residue was purified by column chromatography (AcOEt: $n$-hexane $=1: 1)$ to give 3 as a crystalline solid $(2.2 \mathrm{~g}, 96 \%$ yield). ${ }^{1} \mathrm{H}-\mathrm{NMR}\left(\mathrm{CDCl}_{3}\right) \delta: 1.27(9 \mathrm{H}, \mathrm{s}), 2.11(3 \mathrm{H}, \mathrm{s}), 2.15(3 \mathrm{H}, \mathrm{s}), 2.32$ $(3 \mathrm{H}, \mathrm{s}), 3.04(2 \mathrm{H}, \mathrm{t}, J=8.0 \mathrm{~Hz}), 4.16(2 \mathrm{H}, \mathrm{t}, J=8.0 \mathrm{~Hz}), 9.07(1 \mathrm{H}, \mathrm{s})$

$N$-(4,6-Dimethyl-5-nitroindolin-7-yl)-2,2-dimethylpropanamide (4): To a solution of $3(800 \mathrm{mg}, 2.4 \mathrm{mmol})$ in $\mathrm{MeOH}(8 \mathrm{ml})$ was added $\mathrm{NaOH}$ aqueous solution ( $480 \mathrm{mg}, 12.0 \mathrm{mmol} / 3 \mathrm{ml}$ ), and the mixture was stirred at $80^{\circ} \mathrm{C}$ for $15 \mathrm{~min}$. After evaporation under reduced pressure, the residue was dissolved in $\mathrm{CHCl}_{3}(50 \mathrm{ml})$, and the solution was washed with water and brine, dried over $\mathrm{Na}_{2} \mathrm{SO}_{4}$, and then evaporated under reduced pressure. The residue was purified by column chromatography $\left(\mathrm{CHCl}_{3}: \mathrm{MeOH}=50: 1\right)$ to give 4 as a crystalline solid $\left(680 \mathrm{mg}, 97 \%\right.$ yield). ${ }^{1} \mathrm{H}-\mathrm{NMR}\left(\mathrm{CDCl}_{3}\right) \delta: 1.23(9 \mathrm{H}, \mathrm{s})$, $2.14(3 \mathrm{H}, \mathrm{s}), 2.16(3 \mathrm{H}, \mathrm{s}), 3.01(2 \mathrm{H}, \mathrm{t}, J=8.5 \mathrm{~Hz}), 3.67(2 \mathrm{H}, \mathrm{t}, J=8.5 \mathrm{~Hz})$, $4.26(1 \mathrm{H}, \mathrm{s}), 7.03(1 \mathrm{H}, \mathrm{s})$.

$N$-[1-(2-Ethoxyethyl)-4,6-dimethyl-5-nitroindolin-7-yl]-2,2-dimethylpropanamide (5i): To a solution of $4(50 \mathrm{~g}, 0.17 \mathrm{~mol})$ in $N, N$-dimethylformamide (DMF) $(500 \mathrm{ml})$ were added $i-\operatorname{Pr}_{2} \mathrm{NEt}(58.5 \mathrm{ml}, 0.34 \mathrm{~mol})$ and $2-$ bromoethyl ethyl ether $(58 \mathrm{ml}, 0.51 \mathrm{~mol})$, and the mixture was stirred at $110{ }^{\circ} \mathrm{C}$ for $18 \mathrm{~h}$ under an $\mathrm{N}_{2}$ atmosphere. After cooling, the reaction mixture was diluted with AcOEt (21), and washed with water, 5\% citric acid solution, and brine. The organic layer was dried over $\mathrm{Na}_{2} \mathrm{SO}_{4}$, and evaporated under reduced pressure to give a crystalline product. The products were recrystallized from $\mathrm{MeOH}(60 \mathrm{ml})$ to give $5 \mathbf{i}(45.0 \mathrm{~g}, 72 \%$ yield). IR (Nujol) $\mathrm{cm}^{-1}: 1668 .{ }^{1} \mathrm{H}-\mathrm{NMR}\left(\mathrm{CDCl}_{3}\right) \delta: 1.09(3 \mathrm{H}, \mathrm{t}, J=7.0 \mathrm{~Hz}), 1.21(9 \mathrm{H}$, s), $1.88(3 \mathrm{H}, \mathrm{s}), 2.04(3 \mathrm{H}, \mathrm{s}), 2.89(2 \mathrm{H}, \mathrm{t}, J=8.9 \mathrm{~Hz}), 3.40(2 \mathrm{H}, \mathrm{q}$ $J=7.0 \mathrm{~Hz}), 3.40-3.53(4 \mathrm{H}, \mathrm{m}), 3.62(2 \mathrm{H}, \mathrm{t}, J=8.9 \mathrm{~Hz}), 8.82(1 \mathrm{H}, \mathrm{s})$.

$\mathrm{N}$-[5-(tert-Butoxycarbonylamino)sulfonylamino-1-(2-ethoxyethyl)-4,6-dimethylindolin-7-yl]-2,2-dimethylpropanamide (6i): A suspension of $\mathbf{5 i}$ $(45.0 \mathrm{~g}, 0.12 \mathrm{~mol})$ in $\mathrm{MeOH}(700 \mathrm{ml})$ was hydrogenated at $0.3 \mathrm{MPa}$ in the presence of $10 \% \mathrm{Pd}-\mathrm{C}(9.0 \mathrm{~g})$ at $40{ }^{\circ} \mathrm{C}$ for $20 \mathrm{~h}$. After removal of the catalyst by filtration, the filtrate was evaporated under reduced pressure. The residue was rinsed with $i-\operatorname{Pr}_{2} \mathrm{O}(150 \mathrm{ml})$, and then the precipitate was collected by filtration. $N$-[5-Amino-1-(2-ethoxyethyl)-4,6-dimethylindolin-7-yl]-2,2dimethylpropanamide (30) was obtained as a crystalline solid $(35.0 \mathrm{~g})$. To a stirred solution of tert-BuOH $(15.0 \mathrm{ml}, 0.157 \mathrm{~mol})$ in $\mathrm{CH}_{2} \mathrm{Cl}_{2}(350 \mathrm{ml})$ was added chlorosulfonyl isocyanate $(13.7 \mathrm{ml}, 0.157 \mathrm{~mol})$ at $-10^{\circ} \mathrm{C}$, and then the mixture was stirred at the same temperature for $30 \mathrm{~min}$. To the solution were added $30(35.0 \mathrm{~g}, 0.105 \mathrm{~mol})$ and $\mathrm{Et}_{3} \mathrm{~N}(22.0 \mathrm{ml}, 0.158 \mathrm{~mol})$, and the mixture was stirred for $1 \mathrm{~h}$ at the same temperature. After addition of $\mathrm{CH}_{2} \mathrm{Cl}_{2}$, the solution was washed with $5 \%$ citric acid solution, saturated $\mathrm{NaHCO}_{3}$ solution, water, and brine. The organic layer was dried over $\mathrm{Na}_{2} \mathrm{SO}_{4}$, and evaporated under reduced pressure. The residue was purified by column chromatography (AcOEt: $\mathrm{CHCl}_{3}=1: 1$ ) to give $\mathbf{6 i}$ as a crystalline solid (47.5 g, 75\% yield). ${ }^{1} \mathrm{H}-\mathrm{NMR}\left(\mathrm{DMSO}-d_{6}\right) \delta: 1.08(3 \mathrm{H}, \mathrm{t}, J=7.0 \mathrm{~Hz})$, $1.20(9 \mathrm{H}, \mathrm{s}), 1.43(9 \mathrm{H}, \mathrm{s}), 1.95(3 \mathrm{H}, \mathrm{s}), 2.07(3 \mathrm{H}, \mathrm{s}), 2.77(2 \mathrm{H}, \mathrm{t}, J=8.7 \mathrm{~Hz})$, $3.30-3.50(8 \mathrm{H}, \mathrm{m}), 8.66(1 \mathrm{H}, \mathrm{s}), 9.12(1 \mathrm{H}, \mathrm{s}), 10.70-10.85(1 \mathrm{H}, \mathrm{br})$.

$\mathrm{N}$-[1-(2-Ethoxyethyl)-4,6-dimethyl-5-sulfamoylaminoindolin-7-yl]-2,2-dimethylpropanamide Hydrochloride (1i): To a solution of 6i (47.5 g, $0.93 \mathrm{~mol})$ in $\mathrm{HCO}_{2} \mathrm{H}(190 \mathrm{ml})$ in an ice bath was added $8.7 \mathrm{M} \mathrm{HCl}$ in $i$-PrOH $(32 \mathrm{ml}, 0.28 \mathrm{~mol})$, and the mixture was stirred at the same temperature for $30 \mathrm{~min}$. After the solution had been poured into $\mathrm{Et}_{2} \mathrm{O}$ (5.91) with stirring, the precipitate formed was collected by filtration. To a suspension of the precipitate in $\mathrm{MeOH}(180 \mathrm{ml})$ was added $\mathrm{Et}_{2} \mathrm{O}$ (3.91) with stirring, and the precipitate was collected by filtration to obtain compound $\mathbf{1 i}$ as a crystalline solid (33.5 g, 80\% yield). mp $144-148^{\circ} \mathrm{C}$. IR (Nujol) $\mathrm{cm}^{-1}: 1657 .{ }^{1} \mathrm{H}-\mathrm{NMR}$ $\left(\mathrm{DMSO}-d_{6}\right) \delta: 1.13(3 \mathrm{H}, \mathrm{t}, J=7.0 \mathrm{~Hz}), 1.26(9 \mathrm{H}, \mathrm{s}), 2.11(3 \mathrm{H}, \mathrm{s}), 2.27(3 \mathrm{H}$, s), $3.05-3.15(2 \mathrm{H}, \mathrm{m}), 3.30-3.40(2 \mathrm{H}, \mathrm{m}), 3.45(2 \mathrm{H}, \mathrm{q}, J=7.0 \mathrm{~Hz}), 3.65-$ $3.75(2 \mathrm{H}, \mathrm{m}), 3.75-3.85(2 \mathrm{H}, \mathrm{m}), 8.46(1 \mathrm{H}, \mathrm{s}), 9.16(1 \mathrm{H}, \mathrm{s}) . \mathrm{MS} m / z: 413$ $[\mathrm{M}+\mathrm{H}]^{+}$. Anal. Calcd for $\mathrm{C}_{19} \mathrm{H}_{32} \mathrm{~N}_{4} \mathrm{O}_{4} \mathrm{~S} \cdot \mathrm{HCl} \cdot \mathrm{H}_{2} \mathrm{O}: \mathrm{C}, 48.86 ; \mathrm{H}, 7.55 ; \mathrm{N}$, 12.00; Cl, 7.59. Found: C, 48.87; H, 7.43; N, 11.95; Cl, 7.47.

Procedure for the Synthesis of 1a Compound 1a was synthesized from 4 via $\mathbf{5 a}$ according to the procedure for $\mathbf{1 i}$. The reaction condition of the preparation for $\mathbf{5} \mathbf{a}$ was changed as follows:

$N$-(4,6-Dimethyl-5-nitro-1-propylindolin-7-yl)-2,2-dimethylpropanamide (5a): To a stirred solution of $\mathbf{4}(500 \mathrm{mg}, 1.72 \mathrm{mmol})$ in DMF $(5 \mathrm{ml})$ in an ice bath was added a $60 \%$ suspension of $\mathrm{NaH}$ in mineral oil $(103 \mathrm{mg}, 2.6 \mathrm{mmol})$ portionwise under an $\mathrm{N}_{2}$ atmosphere. After stirring at the same temperature for $15 \mathrm{~min}$, propyl iodide $(0.34 \mathrm{ml}, 3.5 \mathrm{mmol})$ was added to the mixture in an ice bath, and was further stirred for $18 \mathrm{~h}$ at room temperature. After addition of water $(50 \mathrm{ml})$, the reaction mixture was extracted with AcOEt. The organic layer was washed with water and brine, dried over $\mathrm{Na}_{2} \mathrm{SO}_{4}$, and evaporated under reduced pressure. The residue was purified by column chromatography $\left(\mathrm{CHCl}_{3}: \mathrm{MeOH}=50: 1\right)$ to give $\mathbf{5 a}$ as a crystalline solid $(0.42 \mathrm{~g}$, $80 \%$ yield). ${ }^{1} \mathrm{H}-\mathrm{NMR}\left(\mathrm{CDCl}_{3}\right) \delta: 0.91(3 \mathrm{H}, \mathrm{t}, J=7.1 \mathrm{~Hz}), 2.10-2.70(2 \mathrm{H}$, m), $1.33(9 \mathrm{H}, \mathrm{s}), 2.02(3 \mathrm{H}, \mathrm{s}), 2.11(3 \mathrm{H}, \mathrm{s}), 2.89(2 \mathrm{H}, \mathrm{t}, J=8.7 \mathrm{~Hz}), 3.10$ $3.40(2 \mathrm{H}, \mathrm{m}), 3.55(2 \mathrm{H}, \mathrm{t}, J=8.7 \mathrm{~Hz}), 6.77(1 \mathrm{H}, \mathrm{s})$.

$\mathrm{N}$-(4,6-Dimethyl-1-propyl-5-sulfamoylaminoindolin-7-yl)-2,2-dimethylpropanamide Hydrochloride (1a): A crystalline solid. mp $175-178^{\circ} \mathrm{C}$. IR (Nujol) $\mathrm{cm}^{-1}: 1674 .{ }^{1} \mathrm{H}-\mathrm{NMR}\left(\mathrm{DMSO}-d_{6}\right) \delta: 0.86(3 \mathrm{H}, \mathrm{t}, J=7.3 \mathrm{~Hz}), 1.30$ $(9 \mathrm{H}, \mathrm{s}), 1.60-2.00(2 \mathrm{H}, \mathrm{m}), 2.10(3 \mathrm{H}, \mathrm{s}), 2.30(3 \mathrm{H}, \mathrm{s}), 2.90-3.40(4 \mathrm{H}, \mathrm{m})$, $3.65-4.00(2 \mathrm{H}, \mathrm{m}), 5.00-8.00(3 \mathrm{H}, \mathrm{br}), 8.53(1 \mathrm{H}, \mathrm{s}), 9.32(1 \mathrm{H}, \mathrm{s}) . \mathrm{MS}$ $m / z: 383[\mathrm{M}+\mathrm{H}]^{+}$. Anal. Calcd for $\mathrm{C}_{18} \mathrm{H}_{30} \mathrm{~N}_{4} \mathrm{O}_{3} \mathrm{~S} \cdot \mathrm{HCl} \cdot 0.5 \mathrm{H}_{2} \mathrm{O}: \mathrm{C}, 50.51 ; \mathrm{H}$, 7.54; N, 13.09; Cl, 8.28. Found: C, 50.34; H, 7.40; N, 13.01; Cl, 8.24

Procedure for the Synthesis of $\mathbf{1 b}-\mathbf{f}$ Compounds $\mathbf{1 b}-\mathbf{f}$ were synthesized according to the procedure for $\mathbf{1 a}$.

$N$-(1-Butyl-4,6-dimethyl-5-sulfamoylaminoindolin-7-yl)-2,2-dimethylpropanamide Hydrochloride (1b): A crystalline solid. mp $178-181^{\circ} \mathrm{C}$. IR (Nujol) $\mathrm{cm}^{-1}: 1674 .{ }^{1} \mathrm{H}-\mathrm{NMR}$ (DMSO- $\left.d_{6}\right) \delta: 0.70-1.10(3 \mathrm{H}, \mathrm{m}), 1.30(9 \mathrm{H}$, s), $1.40-1.90(4 \mathrm{H}, \mathrm{m}), 2.14(3 \mathrm{H}, \mathrm{s}), 2.30(3 \mathrm{H}, \mathrm{s}), 2.90-3.40(4 \mathrm{H}, \mathrm{m})$, $3.60-3.90(2 \mathrm{H}, \mathrm{m}), 4.50-8.00(3 \mathrm{H}, \mathrm{br}), 8.55(1 \mathrm{H}, \mathrm{s}), 9.33(1 \mathrm{H}, \mathrm{s})$. MS $m / z: 397[\mathrm{M}+\mathrm{H}]^{+}$. Anal. Calcd for $\mathrm{C}_{19} \mathrm{H}_{32} \mathrm{~N}_{4} \mathrm{O}_{3} \mathrm{~S} \cdot \mathrm{HCl} \cdot 0.5 \mathrm{H}_{2} \mathrm{O}: \mathrm{C}, 51.37 ; \mathrm{H}$, 7.65; N, 12.56; Cl, 7.84. Found: C, 51.63; H, 7.75; N, 12.68; Cl, 8.02.

$\mathrm{N}$-(4,6-Dimethyl-1-pentyl-5-sulfamoylaminoindolin-7-yl)-2,2-dimethylpropanamide Hydrochloride (1c): A crystalline solid. mp $170-173{ }^{\circ} \mathrm{C}$. IR (Nujol) $\mathrm{cm}^{-1}$ : $1672 .{ }^{1} \mathrm{H}-\mathrm{NMR}\left(\mathrm{DMSO}-d_{6}\right) \delta: 0.85(3 \mathrm{H}, \mathrm{t}, J=5.7 \mathrm{~Hz}), 1.30$ $(9 \mathrm{H}, \mathrm{s}), 1.50-2.00(6 \mathrm{H}, \mathrm{m}), 2.14(3 \mathrm{H}, \mathrm{s}), 2.30(3 \mathrm{H}, \mathrm{s}), 2.90-3.40(4 \mathrm{H}, \mathrm{m})$, $3.65-4.00(2 \mathrm{H}, \mathrm{m}), 5.00-8.00(3 \mathrm{H}, \mathrm{br}), 8.53(1 \mathrm{H}, \mathrm{s}), 9.32(1 \mathrm{H}, \mathrm{s}) . \mathrm{MS}$ $m / z: 411[\mathrm{M}+\mathrm{H}]^{+}$. Anal. Calcd for $\mathrm{C}_{20} \mathrm{H}_{34} \mathrm{~N}_{4} \mathrm{O}_{3} \mathrm{~S} \cdot \mathrm{HCl} \cdot 0.5 \mathrm{H}_{2} \mathrm{O}: \mathrm{C}, 52.68 ; \mathrm{H}$, 7.96; N, 12.29; Cl, 7.77. Found: C, 52.41; H, 7.84; N, 12.37; Cl, 7.57.

$\mathrm{N}$-(4,6-Dimethyl-1-octyl-5-sulfamoylaminoindolin-7-yl)-2,2-dimethylpropanamide Hydrochloride (1d): A crystalline solid. mp $170-173{ }^{\circ} \mathrm{C}$. IR (Nujol) $\mathrm{cm}^{-1}: 1676 .{ }^{1} \mathrm{H}-\mathrm{NMR}\left(\mathrm{DMSO}-d_{6}\right) \delta: 0.84(3 \mathrm{H}, \mathrm{t}, J=6.0 \mathrm{~Hz}), 1.00$ $1.95(21 \mathrm{H}, \mathrm{m}), 2.13(3 \mathrm{H}, \mathrm{s}), 2.30(3 \mathrm{H}, \mathrm{s}), 2.95-3.50(4 \mathrm{H}, \mathrm{m}), 3.81(2 \mathrm{H}, \mathrm{t}$, $J=6.5 \mathrm{~Hz}), 5.50-9.00(3 \mathrm{H}, \mathrm{br}), 8.55(1 \mathrm{H}, \mathrm{s}), 9.37(1 \mathrm{H}, \mathrm{s}) . \mathrm{MS} m / z: 453$ $[\mathrm{M}+\mathrm{H}]^{+}$. Anal. Calcd for $\mathrm{C}_{23} \mathrm{H}_{40} \mathrm{~N}_{4} \mathrm{O}_{3} \mathrm{~S} \cdot \mathrm{HCl} \cdot 0.5 \mathrm{H}_{2} \mathrm{O}: \mathrm{C}, 55.46 ; \mathrm{H}, 8.50 ; \mathrm{N}$, 11.25; Cl, 7.12. Found: C, 55.63; H, 8.26; N, 11.39; Cl, 7.01.

$N$-[4,6-Dimethyl-1-(2-methylpropyl)-5-sulfamoylaminoindolin-7-yl]-2,2dimethylpropanamide Hydrochloride (1e): A crystalline solid. mp 182$185^{\circ} \mathrm{C}$. IR (Nujol) $\mathrm{cm}^{-1}: 1668 .{ }^{1} \mathrm{H}-\mathrm{NMR}$ (DMSO- $\left.d_{6}\right) \quad \delta: 0.98(6 \mathrm{H}, \mathrm{d}$, $J=6.4 \mathrm{~Hz}), 1.29(9 \mathrm{H}, \mathrm{s}), 1.90-2.30(1 \mathrm{H}, \mathrm{m}), 2.12(3 \mathrm{H}, \mathrm{s}), 2.29(3 \mathrm{H}, \mathrm{s})$, $2.80-3.30(3 \mathrm{H}, \mathrm{m}), 3.60-3.90(2 \mathrm{H}, \mathrm{m}), 5.00-7.50(3 \mathrm{H}, \mathrm{m}), 8.48(1 \mathrm{H}, \mathrm{s})$ $9.27(1 \mathrm{H}, \mathrm{s})$. MS $m / z: 397[\mathrm{M}+\mathrm{H}]^{+}$. Anal. Calcd for $\mathrm{C}_{19} \mathrm{H}_{32} \mathrm{~N}_{4} \mathrm{O}_{3} \mathrm{~S}$. 
$\mathrm{HCl} \cdot \mathrm{H}_{2} \mathrm{O}$ : C, 50.60; H, 7.82; N, 12.42; Cl, 7.86. Found: C, 50.44; H, 7.49; $\mathrm{N}, 12.51 ; \mathrm{Cl}, 7.86$.

$N$-[4,6-Dimethyl-1-(3-methylbutyl)-5-sulfamoylaminoindolin-7-yl]-2,2dimethylpropanamide Hydrochloride (1f): A crystalline solid. mp 181$183{ }^{\circ} \mathrm{C}$. IR (Nujol) $\mathrm{cm}^{-1}: 1672 .{ }^{1} \mathrm{H}-\mathrm{NMR}$ (DMSO- $\left.d_{6}\right) \delta: 0.85(6 \mathrm{H}, \mathrm{d}, J=5.0$ $\mathrm{Hz}), 1.30(9 \mathrm{H}, \mathrm{s}), 1.30-1.80(3 \mathrm{H}, \mathrm{m}), 2.14(3 \mathrm{H}, \mathrm{s}), 2.30(3 \mathrm{H}, \mathrm{s}), 2.90$ $3.40(4 \mathrm{H}, \mathrm{m}), 3.60-4.00(2 \mathrm{H}, \mathrm{m}), 5.50-7.50(2 \mathrm{H}, \mathrm{br}), 8.54(1 \mathrm{H}, \mathrm{s}), 9.30$ $(1 \mathrm{H}, \mathrm{s})$. MS $m / z: 411[\mathrm{M}+\mathrm{H}]^{+}$. Anal. Calcd for $\mathrm{C}_{20} \mathrm{H}_{34} \mathrm{~N}_{4} \mathrm{O}_{3} \mathrm{~S} \cdot \mathrm{HCl} \cdot \mathrm{H}_{2} \mathrm{O}: \mathrm{C}$, 51.65; H, 8.02; N, 12.05; Cl, 7.62. Found: C, 51.83; H, 7.98; N, 12.02; Cl, 7.64 .

Procedure for the Synthesis of $1 \mathrm{~h}$ Compound $\mathbf{1 h}$ was synthesized from $\mathbf{4}$ in a similar manner to the procedure for $\mathbf{1 i}$.

$N$-[1-(2-Methoxyethyl)-4,6-dimethyl-5-sulfamoylaminoindolin-7-yl]-2,2dimethylpropanamide Hydrochloride (1h): A crystalline solid. mp 160$163{ }^{\circ} \mathrm{C}$. IR (Nujol) $\mathrm{cm}^{-1}: 1680 .{ }^{1} \mathrm{H}-\mathrm{NMR}$ (DMSO- $\left.d_{6}\right) \delta: 1.25(9 \mathrm{H}, \mathrm{s}), 2.10$ $(3 \mathrm{H}, \mathrm{s}), 2.24(3 \mathrm{H}, \mathrm{s}), 3.00-3.10(2 \mathrm{H}, \mathrm{m}), 3.27(3 \mathrm{H}, \mathrm{s}), 3.35(2 \mathrm{H}, \mathrm{t}$ $J=5.2 \mathrm{~Hz}), 3.59-3.80(4 \mathrm{H}, \mathrm{m}), 6.40-7.10(2 \mathrm{H}, \mathrm{br}), 8.39(1 \mathrm{H}, \mathrm{s}), 9.02(1 \mathrm{H}$ s). MS m/z: $399[\mathrm{M}+\mathrm{H}]^{+}$. Anal. Calcd for $\mathrm{C}_{18} \mathrm{H}_{30} \mathrm{~N}_{4} \mathrm{O}_{4} \mathrm{~S} \cdot \mathrm{HCl} \cdot 0.8 \mathrm{H}_{2} \mathrm{O}: \mathrm{C}$ 48.11; H, 7.31; N, 12.47; Cl, 7.89. Found: C, 47.91; H, 6.97; N, 12.43; Cl, 7.97.

Procedure for the Synthesis of $\mathbf{1 g}$ Compound $\mathbf{1 g}$ was synthesized from 3 via 7 and $\mathbf{6 g}$. Compound $\mathbf{6 g}$ was converted to $\mathbf{1 g}$ according to the procedure for $1 \mathbf{i}$. Compound $\mathbf{6 g}$ was prepared via $\mathbf{3 1}, \mathbf{3 3}$, and 7 as follows:

$N$-(1-Acetyl-5-tert-butoxycarbonylamino-4,6-dimethylindolin-7-yl)-2,2dimethylpropanamide (31): A solution of $3(20.0 \mathrm{~g}, 60.0 \mathrm{mmol})$ in $\mathrm{MeOH}$ $(300 \mathrm{ml})$ was hydrogenated at $0.3 \mathrm{MPa}$ in the presence of $5 \% \mathrm{Pd}-\mathrm{C}(200 \mathrm{mg})$ at room temperature for $20 \mathrm{~h}$. After removal of the catalyst by filtration, the filtrate was evaporated under reduced pressure. The solid residue was rinsed with $\mathrm{Et}_{2} \mathrm{O}$ to give $\mathrm{N}$-(1-acetyl-5-amino-4,6-dimethylindolin-7-yl)-2,2-dimethylpropanamide (32) as a solid $(17.0 \mathrm{~g}, 93 \%$ yield). A mixture of $32(5.0 \mathrm{~g}$ $16 \mathrm{mmol}), \mathrm{Boc}_{2} \mathrm{O}(10.8 \mathrm{~g}, 49.5 \mathrm{mmol})$, and $\mathrm{Et}_{3} \mathrm{~N}(6.9 \mathrm{ml}, 49 \mathrm{mmol})$ was stirred at $90^{\circ} \mathrm{C}$ for $17 \mathrm{~h}$. After addition of water $(50 \mathrm{ml})$, the reaction mixture was extracted with $\mathrm{CHCl}_{3}$. The organic layer was washed with $10 \%$ citric acid solution, saturated $\mathrm{NaHCO}_{3}$ solution and brine, dried over $\mathrm{Na}_{2} \mathrm{SO}_{4}$, and evaporated under reduced pressure. The residue was purified by column chromatography $\left(\mathrm{CHCl}_{3}: n\right.$-hexane $\left.=4: 1\right)$ to give $\mathbf{3 1}$ as an oil $(2.44 \mathrm{~g}, 37 \%$ yield). ${ }^{1} \mathrm{H}-\mathrm{NMR}\left(\mathrm{CDCl}_{3}\right) \delta: 1.27(9 \mathrm{H}, \mathrm{s}), 1.47(9 \mathrm{H}, \mathrm{s}), 2.08(3 \mathrm{H}, \mathrm{s}), 2.13$ $(3 \mathrm{H}, \mathrm{s}), 2.29(3 \mathrm{H}, \mathrm{s}), 2.70-3.30(2 \mathrm{H}, \mathrm{m}), 4.10(2 \mathrm{H}, \mathrm{br}-\mathrm{t}), 5.85(1 \mathrm{H}, \mathrm{s}), 9.20$ $(1 \mathrm{H}, \mathrm{s})$.

$N$-(5-tert-Butoxycarbonylamino-4,6-dimethylindolin-7-yl)-2,2-dimethylpropanamide (33): To a solution of $31(2.40 \mathrm{~g}, 5.95 \mathrm{mmol})$ in EtOH $(24 \mathrm{ml})$ was added $5.0 \mathrm{M} \mathrm{NaOH}$ aqueous solution $(6 \mathrm{ml}, 30 \mathrm{mmol})$, and the mixture was refluxed for $1 \mathrm{~h}$. After addition of water $(75 \mathrm{ml})$, the reaction mixture was stirred for $15 \mathrm{~min}$ at room temperature. The precipitate formed was collected by filtration to obtain 33 as a crystalline solid $\left(1.47 \mathrm{~g}, 68 \%\right.$ yield). ${ }^{1} \mathrm{H}-$ NMR $\left(\mathrm{CDCl}_{3}\right) \delta: 1.32(9 \mathrm{H}, \mathrm{s}), 1.46(9 \mathrm{H}, \mathrm{s}), 2.07(3 \mathrm{H}, \mathrm{s}), 2.09(3 \mathrm{H}, \mathrm{s})$ $2.20-3.30(1 \mathrm{H}$, br), $2.95(2 \mathrm{H}, \mathrm{t}, J=8.1 \mathrm{~Hz}), 3.57(2 \mathrm{H}, \mathrm{t}, J=8.1 \mathrm{~Hz}), 5.77$ $(1 \mathrm{H}, \mathrm{s}), 7.06(1 \mathrm{H}, \mathrm{s})$.

$N$-(5-tert-Butoxycarbonylamino-1-cyclopentyl-4,6-dimethylindolin-7-yl)2,2-dimethylpropanamide (7): To a solution of $33(3.14 \mathrm{~g}, 8.69 \mathrm{mmol})$ in DMF $(30 \mathrm{ml})$ were added $i-\operatorname{Pr}_{2} \mathrm{NEt}(3.0 \mathrm{ml}, 17 \mathrm{mmol})$, bromocyclopentane $(1.86 \mathrm{ml}, 17.4 \mathrm{mmol}), \mathrm{KI}(721 \mathrm{mg}, 4.34 \mathrm{mmol})$, and hydroquinone (48 $\mathrm{mg}$ $0.44 \mathrm{mmol}$ ), and the mixture was stirred for $15 \mathrm{~h}$ at $90{ }^{\circ} \mathrm{C}$. After the mixture was poured into water $(100 \mathrm{ml})$, the precipitate formed was collected by filtration. A solution of the obtained powder in $\mathrm{CHCl}_{3}(100 \mathrm{ml})$ was washed with water and brine, dried over $\mathrm{Na}_{2} \mathrm{SO}_{4}$, and evaporated under reduced pressure. The residue was purified by column chromatography (AcOEt: $\mathrm{CHCl}_{3}=1: 5$ ) to give a crystalline powder. The powder was rinsed with $i-\mathrm{Pr}_{2} \mathrm{O}$ to give 7 as a crystalline solid $(0.78 \mathrm{~g}, 21 \%$ yield $) .{ }^{1} \mathrm{H}-\mathrm{NMR}$ $\left(\mathrm{CDCl}_{3}\right) \delta: 1.32(9 \mathrm{H}, \mathrm{s}), 1.30-1.80(8 \mathrm{H}, \mathrm{m}), 1.49(9 \mathrm{H}, \mathrm{s}), 1.99(3 \mathrm{H}, \mathrm{s}), 2.06$ $(3 \mathrm{H}, \mathrm{s}), 2.84(2 \mathrm{H}, \mathrm{t}, J=8.3 \mathrm{~Hz}), 3.41(2 \mathrm{H}, \mathrm{t}, J=8.3 \mathrm{~Hz}), 4.20-4.30(1 \mathrm{H}, \mathrm{m})$, $5.75(1 \mathrm{H}, \mathrm{s}), 6.85(1 \mathrm{H}, \mathrm{s})$

$\mathrm{N}$-[5-(tert-Butoxycarbonylamino)sulfonylamino-1-cyclopentyl-4,6-dimethylindolin-7-yl]-2,2-dimethylpropanamide $(\mathbf{6 g})$ : To a solution of 7 $(0.76 \mathrm{~g}, 1.8 \mathrm{mmol})$ in $\mathrm{HCO}_{2} \mathrm{H}(7.6 \mathrm{ml})$ in an ice bath was added $8.7 \mathrm{M} \mathrm{HCl}$ in $i$-PrOH $(0.61 \mathrm{ml}, 5.3 \mathrm{mmol})$, and the mixture was stirred at the same temperature for $15 \mathrm{~min}$. After addition of a mixed solvent of $i-\mathrm{Pr}_{2} \mathrm{O}-n$-hexane, the supernatant was removed by decantation to give an oily product. A solution of the oil in AcOEt $(100 \mathrm{ml})$ was washed with saturated $\mathrm{NaHCO}_{3}$ solution and brine, dried over $\mathrm{Na}_{2} \mathrm{SO}_{4}$, and evaporated under reduced pressure. The residue was treated with chlorosulfonyl isocyanate according to the method of preparation for $\mathbf{6 i}$ to give $\mathbf{6} \mathbf{g}$ as a crystalline solid (618 $\mathrm{mg}, 69 \%$ yield) ${ }^{1} \mathrm{H}-\mathrm{NMR}$ (DMSO- $d_{6}$ ) $\delta: 1.23(9 \mathrm{H}, \mathrm{s}), 1.30-1.80(8 \mathrm{H}, \mathrm{m}), 1.43(9 \mathrm{H}, \mathrm{s}), 1.99$ $(3 \mathrm{H}, \mathrm{s}), 2.12(3 \mathrm{H}, \mathrm{s}), 2.60-3.10(2 \mathrm{H}, \mathrm{m}), 4.00-4.80(3 \mathrm{H}, \mathrm{m}), 8.88(1 \mathrm{H}, \mathrm{s})$
$9.24(1 \mathrm{H}, \mathrm{s}), 10.82(1 \mathrm{H}, \mathrm{s})$.

$\mathrm{N}$-(1-Cyclopentyl-4,6-dimethyl-5-sulfamoylaminoindolin-7-yl)-2,2-dimethylpropanamide Hydrochloride (1g): A crystalline solid. Yield 89\%. mp $173-176^{\circ} \mathrm{C}$. IR (Nujol) $\mathrm{cm}^{-1}: 1665 .{ }^{1} \mathrm{H}-\mathrm{NMR}\left(\mathrm{DMSO}-d_{6}\right) \delta: 1.30(9 \mathrm{H}, \mathrm{s})$, $1.40-1.80(8 \mathrm{H}, \mathrm{m}), 2.13(3 \mathrm{H}, \mathrm{s}), 2.27(3 \mathrm{H}, \mathrm{s}), 3.00-3.20(2 \mathrm{H}, \mathrm{m}), 3.20$ $3.80(4 \mathrm{H}, \mathrm{m}), 3.90-4.00(1 \mathrm{H}, \mathrm{m}), 6.70-7.00(1 \mathrm{H}, \mathrm{br}), 8.50(1 \mathrm{H}, \mathrm{s}), 9.23$ $(1 \mathrm{H}, \mathrm{s}) . \mathrm{MS} m / z: 409[\mathrm{M}+\mathrm{H}]^{+}$. Anal. Calcd for $\mathrm{C}_{20} \mathrm{H}_{32} \mathrm{~N}_{4} \mathrm{O}_{3} \mathrm{~S} \cdot \mathrm{HCl} \cdot 1.2 \mathrm{H}_{2} \mathrm{O}$ C, 51.48; H, 7.65; N, 12.01; Cl, 7.60. Found: C, 51.45; H, 7.60; N, 11.87 $\mathrm{Cl}, 7.27$.

Procedure for the Synthesis of $\mathbf{1 j}$ Compound $\mathbf{1} \mathbf{j}$ was synthesized from $\mathbf{4}$ via $\mathbf{5} \mathbf{j}$. Compound $\mathbf{5} \mathbf{j}$ was converted to $\mathbf{1} \mathbf{j}$ according to the procedure for 1i. Compound $\mathbf{5} \mathbf{j}$ was prepared as follows:

$N$-[1-(2-Hydroxyethyl)-4,6-dimethyl-5-nitroindolin-7-yl]-2,2-dimethylpropanamide (34): To a solution of $4(8.0 \mathrm{~g}, 28 \mathrm{mmol})$ in DMF $(40 \mathrm{ml})$ were added $i$ - $\operatorname{Pr}_{2} \mathrm{NEt}(14 \mathrm{ml}, 82 \mathrm{mmol})$ and 2-bromoethanol $(5.8 \mathrm{ml}, 82 \mathrm{mmol})$, and the mixture was stirred for $6.5 \mathrm{~h}$ at $120^{\circ} \mathrm{C}$ under an $\mathrm{N}_{2}$ atmosphere. After addition of $5 \%$ citric acid solution $(200 \mathrm{ml})$, the mixture was extracted with AcOEt. The organic layer was washed with $5 \% \mathrm{NaHCO}_{3}$ solution and brine, dried over $\mathrm{Na}_{2} \mathrm{SO}_{4}$, and evaporated under reduced pressure. The crystalline residue was rinsed with $\mathrm{CHCl}_{3}(50 \mathrm{ml})$ to obtain $34(4.88 \mathrm{~g}, 53 \%$ yield). The filtrate was evaporated under reduced pressure and purified by column chromatography (AcOEt: $\mathrm{CHCl}_{3}=1: 3$ ). The crystalline residue was rinsed with AcOEt to obtain 34 (1.33 g, 14\% yield). ${ }^{1} \mathrm{H}-\mathrm{NMR}\left(\mathrm{CDCl}_{3}\right) \delta$ : $1.21(9 \mathrm{H}, \mathrm{s}), 1.88(3 \mathrm{H}, \mathrm{s}), 2.04(3 \mathrm{H}, \mathrm{s}), 2.89(2 \mathrm{H}, \mathrm{t}, J=7.1 \mathrm{~Hz}), 3.30-3.40$ $(2 \mathrm{H}, \mathrm{m}), 3.45-3.60(2 \mathrm{H}, \mathrm{m}), 3.65(2 \mathrm{H}, \mathrm{t}, J=7.1 \mathrm{~Hz}), 4.79(1 \mathrm{H}, \mathrm{t}$ $J=4.9 \mathrm{~Hz}), 8.85(1 \mathrm{H}, \mathrm{s})$

$N$-[1-(2-Mercaptoethyl)-4,6-dimethyl-5-nitroindolin-7-yl]-2,2-dimethylpropanamide (35): To a solution of $34(6.21 \mathrm{~g}, 18.5 \mathrm{mmol})$ in $\mathrm{CHCl}_{3}(62 \mathrm{ml})$ in an ice bath were added $\mathrm{MsCl}(2.8 \mathrm{ml}, 36 \mathrm{mmol})$ and $\mathrm{Et}_{3} \mathrm{~N}(5.1 \mathrm{ml}$, $36 \mathrm{mmol}$ ), and the mixture was stirred for $30 \mathrm{~min}$ at the same temperature. After addition of AcOEt, the mixture was washed with 5\% citric acid solution, saturated $\mathrm{NaHCO}_{3}$ solution and brine, dried over $\mathrm{Na}_{2} \mathrm{SO}_{4}$, and evaporated under reduced pressure. The crystalline residue was rinsed with $\mathrm{Et}_{2} \mathrm{O}$ to give a mesylate derivative. To a solution of the obtained solid ( $7.38 \mathrm{~g}$, $17.8 \mathrm{mmol})$ in DMF $(73 \mathrm{ml})$ was added potassium thioacetate $(3.05 \mathrm{~g}$, $26.7 \mathrm{mmol}$ ), and the mixture was stirred for $30 \mathrm{~min}$ at $70^{\circ} \mathrm{C}$. After addition of water, the mixture was extracted with AcOEt. The extract was washed with water and brine, dried over $\mathrm{Na}_{2} \mathrm{SO}_{4}$, and evaporated under reduced pressure. The crystalline residue was rinsed with $\mathrm{Et}_{2} \mathrm{O}$ to give a thioacetate derivative as a solid. To a solution of the solid $(6.5 \mathrm{~g}, 17 \mathrm{mmol})$ in $\mathrm{MeOH}$ $(130 \mathrm{ml})$ in an ice bath was added $2.0 \mathrm{M} \mathrm{NaOH}$ aqueous solution $(9.9 \mathrm{ml}$, $20 \mathrm{mmol}$ ), and the mixture was stirred for $1 \mathrm{~h}$ at the same temperature. After addition of $5 \%$ citric acid solution, the mixture was evaporated under reduced pressure, and then the residue was extracted with AcOEt. The organic layer was washed with water and brine, dried over $\mathrm{Na}_{2} \mathrm{SO}_{4}$, and evaporated under reduced pressure. The crystalline residue was rinsed with $\mathrm{Et}_{2} \mathrm{O}$ to obtain $35\left(5.54 \mathrm{~g}, 85 \%\right.$ yield). ${ }^{1} \mathrm{H}-\mathrm{NMR}\left(\mathrm{CDCl}_{3}\right) \delta: 1.36(9 \mathrm{H}, \mathrm{s}), 1.43(1 \mathrm{H}, \mathrm{t}$, $J=7.8 \mathrm{~Hz}), 2.02(3 \mathrm{H}, \mathrm{s}), 2.11(3 \mathrm{H}, \mathrm{s}), 2.67(2 \mathrm{H}, \mathrm{td}, J=7.8,7.1 \mathrm{~Hz}), 2.94$ $(2 \mathrm{H}, \mathrm{t}, J=9.0 \mathrm{~Hz}), 3.50(2 \mathrm{H}, \mathrm{t}, J=7.8 \mathrm{~Hz}), 3.57(2 \mathrm{H}, \mathrm{t}, J=9.0 \mathrm{~Hz}), 6.97(1 \mathrm{H}$, s).

$N$-[4,6-Dimethyl-1-(2-methylthioethyl)-5-nitroindolin-7-yl]-2,2-dimethylpropanamide $(\mathbf{5 j})$ : To a solution of $\mathbf{3 5}(1.5 \mathrm{~g}, 4.3 \mathrm{mmol})$ in DMF $(15 \mathrm{ml})$ were added $i$-Pr ${ }_{2} \mathrm{NEt}(1.45 \mathrm{ml}, 8.5 \mathrm{mmol})$ and methyl iodide $(0.53 \mathrm{ml}$, $8.5 \mathrm{mmol}$ ), and the mixture was stirred for $0.5 \mathrm{~h}$ at room temperature. After dilution with AcOEt, the mixture was washed with 5\% citric acid solution, water and brine, dried over $\mathrm{Na}_{2} \mathrm{SO}_{4}$, and evaporated under reduced pressure. The crystalline residue was rinsed with $i$ - $\operatorname{Pr}_{2} \mathrm{O}$ to obtain $\mathbf{5 j}(1.42 \mathrm{~g}, 91 \%$ yield). ${ }^{1} \mathrm{H}-\mathrm{NMR}\left(\mathrm{CDCl}_{3}\right) \delta: 1.36(9 \mathrm{H}, \mathrm{s}), 2.03(3 \mathrm{H}, \mathrm{s}), 2.11(3 \mathrm{H}, \mathrm{s}), 2.13$ $(3 \mathrm{H}, \mathrm{s}), 2.66(2 \mathrm{H}, \mathrm{t}, J=7.3 \mathrm{~Hz}), 2.93(2 \mathrm{H}, \mathrm{t}, J=8.8 \mathrm{~Hz}), 3.52(2 \mathrm{H}, \mathrm{t}$, $J=7.3 \mathrm{~Hz}), 3.61(2 \mathrm{H}, \mathrm{t}, J=8.8 \mathrm{~Hz}), 6.98(1 \mathrm{H}, \mathrm{s})$.

$N$-[4,6-Dimethyl-1-(2-methylthioethyl)-5-sulfamoylaminoindolin-7-yl]2,2-dimethylpropanamide Hydrochloride (1j): A crystalline solid. mp 152$156{ }^{\circ} \mathrm{C}$. IR (neat) $\mathrm{cm}^{-1}: 1674 .{ }^{1} \mathrm{H}-\mathrm{NMR}\left(\mathrm{CDCl}_{3}\right) \delta: 1.26(9 \mathrm{H}, \mathrm{s}), 2.07(3 \mathrm{H}$, s), $2.09(3 \mathrm{H}, \mathrm{s}), 2.23(3 \mathrm{H}, \mathrm{s}), 2.65-2.75(3 \mathrm{H}, \mathrm{m}), 2.99-3.06(3 \mathrm{H}, \mathrm{m})$, $3.30-3.40(2 \mathrm{H}, \mathrm{m}), 3.40-4.20(4 \mathrm{H}, \mathrm{m}), 8.35(1 \mathrm{H}, \mathrm{s}), 9.00(1 \mathrm{H}, \mathrm{s})$. MS $m / z$ : $413[\mathrm{M}-\mathrm{H}]^{-}$. Anal. Calcd for $\mathrm{C}_{18} \mathrm{H}_{30} \mathrm{~N}_{4} \mathrm{O}_{3} \mathrm{~S}_{2} \cdot \mathrm{HCl} \cdot 0.5 \mathrm{H}_{2} \mathrm{O}: \mathrm{C}, 46.99 ; \mathrm{H}$, 7.01; N, 12.18; Cl, 7.71. Found: C, 46.75; H, 6.68; N, 12.14; Cl, 7.63.

Procedure for the Synthesis of $1 \mathbf{k}$ Compound $1 \mathbf{k}$ was synthesized from $\mathbf{4}$ according to the procedure for $\mathbf{1 j}$. EtI was used instead of MeI.

$N$-[1-(2-Ethylthioethyl)-4,6-dimethyl-5-sulfamoylaminoindolin-7-yl]-2,2dimethylpropanamide Hydrochloride (1k): A crystalline solid. mp 143$146{ }^{\circ} \mathrm{C}$. IR (Nujol) $\mathrm{cm}^{-1}: 1665 .{ }^{1} \mathrm{H}-\mathrm{NMR}\left(\mathrm{CDCl}_{3}\right) \delta: 1.16(3 \mathrm{H}, \mathrm{t}, J=7.3 \mathrm{~Hz})$, $1.27(9 \mathrm{H}, \mathrm{s}), 2.09(3 \mathrm{H}, \mathrm{s}), 2.24(3 \mathrm{H}, \mathrm{s}), 2.53(2 \mathrm{H}, \mathrm{q}, J=7.3 \mathrm{~Hz}), 2.70-2.80$ $(2 \mathrm{H}, \mathrm{m}), 3.06(2 \mathrm{H}, \mathrm{t}, J=7.8 \mathrm{~Hz}), 3.30-3.40(2 \mathrm{H}, \mathrm{m}), 3.70(2 \mathrm{H}, \mathrm{t}$, 
$J=7.8 \mathrm{~Hz}), 6.30-7.20$ (2H, br), $8.39(1 \mathrm{H}, \mathrm{s}), 9.05(1 \mathrm{H}, \mathrm{s})$. MS $m / z: 429$ $[\mathrm{M}+\mathrm{H}]^{+}$. Anal. Calcd for $\mathrm{C}_{19} \mathrm{H}_{32} \mathrm{~N}_{4} \mathrm{O}_{3} \mathrm{~S}_{2} \cdot \mathrm{HCl} \cdot \mathrm{H}_{2} \mathrm{O}: \mathrm{C}, 47.24 ; \mathrm{H}, 7.30 ; \mathrm{N}$, 11.60; Cl, 7.34. Found: C, 47.08; H, 6.84; N, 11.61; Cl, 7.47.

Procedure for the Synthesis of 9a Compound 9a was synthesized from 10 via 11 and 12. To compound 12 was introduced a pivaloylamino moiety at the 7-position according to the previous report ${ }^{11)}$ and then the product was converted to 9a according to the procedure for 1a. Compound $\mathbf{1 1}$ and $\mathbf{1 2}$ were prepared as follows

2,4,6-Trimethylindole (11): To a mixture of $\mathbf{1 0}^{14)}$ (533 $\left.\mathrm{mg}, 3.91 \mathrm{mmol}\right)$ and acetone $(0.29 \mathrm{ml}, 3.9 \mathrm{mmol})$ was added polyphosphoric acid $(1.5 \mathrm{~g})$, and the mixture was heated gradually until $140^{\circ} \mathrm{C}$ for $30 \mathrm{~min}$. After addition of water $(10 \mathrm{ml})$, the mixture was extracted with $\mathrm{Et}_{2} \mathrm{O}$. The organic layer was washed with water, saturated $\mathrm{NaHCO}_{3}$ solution, and brine, dried over $\mathrm{Na}_{2} \mathrm{SO}_{4}$, and evaporated under reduced pressure. The residue was purified by column chromatography (AcOEt: $n$-hexane $=1: 20$ ) to give $\mathbf{1 1}$ as a crystalline solid (500 mg, 80\% yield). ${ }^{1} \mathrm{H}-\mathrm{NMR}\left(\mathrm{CDCl}_{3}\right) \delta: 2.39(6 \mathrm{H}, \mathrm{s}), 2.45$ $(3 \mathrm{H}, \mathrm{s}), 6.15(1 \mathrm{H}, \mathrm{s}), 6.70(1 \mathrm{H}, \mathrm{s}), 6.87(1 \mathrm{H}, \mathrm{s})$.

1-Acetyl-2,4,6-trimethylindoline (12): To a solution of 11 (480 mg, $3.01 \mathrm{mmol})$ in $\mathrm{AcOH}(2 \mathrm{ml})$ in an ice bath was added $\mathrm{NaBH}_{3} \mathrm{CN}(378 \mathrm{mg}$, $6.02 \mathrm{mmol}$ ), and then the mixture was stirred for $2 \mathrm{~h}$. After the mixture was poured into cold water $(8 \mathrm{ml})$, AcOEt $(5 \mathrm{ml})$ was added, and then the mixture was neutralized with $\mathrm{NaOH}$. The organic layer was separated, washed with water, dried over $\mathrm{Na}_{2} \mathrm{SO}_{4}$, and evaporated under reduced pressure. To a solution of the residue in benzene $(2 \mathrm{ml})$ was added $\mathrm{Ac}_{2} \mathrm{O}(0.4 \mathrm{ml}, 4 \mathrm{mmol})$, and then the mixture was stirred for $1 \mathrm{~h}$. After removal of the solvent under reduced pressure, a solution of the residue in $\mathrm{CHCl}_{3}(50 \mathrm{ml})$ was washed with water, saturated $\mathrm{NaHCO}_{3}$ solution, and brine, dried over $\mathrm{Na}_{2} \mathrm{SO}_{4}$, and evaporated under reduced pressure. The residue was purified by column chromatography (AcOEt: $n$-hexane $=1: 1)$ to give $\mathbf{1 2}$ as a crystalline solid (520 mg, 85\% yield). ${ }^{1} \mathrm{H}-\mathrm{NMR}\left(\mathrm{CDCl}_{3}\right) \delta: 1.28(3 \mathrm{H}, \mathrm{d}, J=6.4 \mathrm{~Hz}), 2.19$ $(3 \mathrm{H}, \mathrm{s}), 2.30(6 \mathrm{H}, \mathrm{s}), 2.40-3.40(2 \mathrm{H}, \mathrm{m}), 4.47-4.57(1 \mathrm{H}, \mathrm{m}), 6.83(1 \mathrm{H}, \mathrm{s})$, $7.81(1 \mathrm{H}, \mathrm{s})$.

$N$-(2,4,6-Trimethyl-1-propyl-5-sulfamoylaminoindolin-7-yl)-2,2-dimethylpropanamide Hydrochloride (9a): A crystalline solid. mp 156 $160{ }^{\circ} \mathrm{C}$. IR (Nujol) $\mathrm{cm}^{-1}: 1666 .{ }^{1} \mathrm{H}-\mathrm{NMR}\left(\mathrm{DMSO}-d_{6}\right) \delta: 0.83(3 \mathrm{H}, \mathrm{t}$, $J=7.1 \mathrm{~Hz}), 1.29(9 \mathrm{H}, \mathrm{s}), 1.39(3 \mathrm{H}, \mathrm{d}, J=6.1 \mathrm{~Hz}), 1.50-1.85(2 \mathrm{H}, \mathrm{m}), 2.12$ $(3 \mathrm{H}, \mathrm{s}), 2.26(3 \mathrm{H}, \mathrm{s}), 2.68-2.80(1 \mathrm{H}, \mathrm{m}), 2.95-3.05(1 \mathrm{H}, \mathrm{m}), 3.20-3.30$ $(1 \mathrm{H}, \mathrm{m}), 3.35-4.00(2 \mathrm{H}, \mathrm{m}), 4.15-4.40(1 \mathrm{H}, \mathrm{m}), 6.50-7.50(2 \mathrm{H}, \mathrm{br}), 8.49$ $(1 \mathrm{H}, \mathrm{s}), 9.30-9.70\left(1 \mathrm{H}\right.$, br). MS m/z: $397[\mathrm{M}+\mathrm{H}]^{+}$. Anal. Calcd for $\mathrm{C}_{19} \mathrm{H}_{32} \mathrm{~N}_{4} \mathrm{O}_{4} \mathrm{~S} \cdot \mathrm{HCl} \cdot \mathrm{H}_{2} \mathrm{O} \cdot 0.1 \mathrm{Et}_{2} \mathrm{O}: \mathrm{C}, 49.11 ; \mathrm{H}, 7.65 ; \mathrm{N}, 11.81 ; \mathrm{Cl}, 7.47$ Found: C, 48.95; H, 7.35; N, 11.93; Cl, 7.24.

Procedure for the Synthesis of $9 b$ and $9 c$ Compounds $9 b$ and $9 c$ were synthesized from $\mathbf{1 2}$ according to the procedure for $\mathbf{9 a}$.

$N$-[1-(2-Methoxyethyl)-2,4,6-trimethyl-5-sulfamoylaminoindolin-7-yl]2,2-dimethylpropanamide Hydrochloride (9b): A crystalline solid. mp $164-167^{\circ} \mathrm{C}$. IR (Nujol) $\mathrm{cm}^{-1}: 1653 .{ }^{1} \mathrm{H}-\mathrm{NMR}$ (DMSO- $\left.d_{6}\right) \delta: 1.25(9 \mathrm{H}, \mathrm{s})$, $1.34(3 \mathrm{H}, \mathrm{d}, J=6.1 \mathrm{~Hz}), 2.10(3 \mathrm{H}, \mathrm{s}), 2.22(3 \mathrm{H}, \mathrm{s}), 2.45-2.70(1 \mathrm{H}, \mathrm{m})$, $3.15-3.45(1 \mathrm{H}, \mathrm{m}), 3.26(3 \mathrm{H}, \mathrm{s}), 3.40-3.70(4 \mathrm{H}, \mathrm{m}), 3.90(1 \mathrm{H}, \mathrm{s}), 4.00$ 4.30 (1H, br), 6.20-7.20 (2H, br), $8.37(1 \mathrm{H}, \mathrm{s}), 9.22(1 \mathrm{H}, \mathrm{s}) . \mathrm{MS} m / z: 411$ $[\mathrm{M}-\mathrm{H}]^{-}$. Anal. Calcd for $\mathrm{C}_{19} \mathrm{H}_{32} \mathrm{~N}_{4} \mathrm{O}_{4} \mathrm{~S} \cdot \mathrm{HCl} \cdot \mathrm{H}_{2} \mathrm{O}: \mathrm{C}, 50.42 ; \mathrm{H}, 7.44 ; \mathrm{N}$, 12.38; Cl, 7.83. Found: C, 50.45; H, 7.35; N, 12.29; Cl, 7.60.

$N$-[1-(2-Ethoxyethyl)-2,4,6-trimethyl-5-sulfamoylaminoindolin-7-yl]-2,2dimethylpropanamide Hydrochloride (9c): A crystalline solid. mp 165$168^{\circ} \mathrm{C}$. IR (Nujol) $\mathrm{cm}^{-1}:$ 1654. ${ }^{1} \mathrm{H}-\mathrm{NMR}$ (DMSO-d $) \delta: 1.12(3 \mathrm{H}, \mathrm{t}$ $J=7.1 \mathrm{~Hz}), 1.26(9 \mathrm{H}, \mathrm{s}), 1.34(3 \mathrm{H}, \mathrm{d}, J=5.9 \mathrm{~Hz}), 2.10(3 \mathrm{H}, \mathrm{s}), 2.22(3 \mathrm{H}, \mathrm{s})$, $2.50-2.70(1 \mathrm{H}, \mathrm{m}), 3.15-3.55(7 \mathrm{H}, \mathrm{m}), 4.00-4.40(2 \mathrm{H}, \mathrm{br}), 6.40-7.20$ $\left(2 \mathrm{H}\right.$, br), $8.37(1 \mathrm{H}, \mathrm{s}), 9.15-9.40(1 \mathrm{H}, \mathrm{br}) . \mathrm{MS} m / z: 427[\mathrm{M}+\mathrm{H}]^{+}$. Anal. Calcd for $\mathrm{C}_{20} \mathrm{H}_{34} \mathrm{~N}_{4} \mathrm{O}_{4} \mathrm{~S} \cdot \mathrm{HCl} \cdot 0.5 \mathrm{H}_{2} \mathrm{O}: \mathrm{C}, 50.89 ; \mathrm{H}, 7.69 ; \mathrm{N}, 11.87 ; \mathrm{Cl}, 7.51$. Found: C, 50.66; H, 7.41; N, 11.84; Cl, 7.48.

Procedure for the Synthesis of 9d Compound 9d was synthesized from 13 via $\mathbf{1 4}$ and $\mathbf{1 5}$. Compound $\mathbf{1 5}$ was converted to $9 \mathrm{~d}$ according to the procedure for 9a. Compound $\mathbf{1 5}$ was prepared as follows:

4,6-Dimethylindole-2-carbaldehyde (14): To a suspension of $\mathrm{LiAlH}_{4}$ $(4.11 \mathrm{~g}, 108 \mathrm{mmol})$ in $\mathrm{Et}_{2} \mathrm{O}(320 \mathrm{ml})$ in an ice bath was added $13^{12)}(15.7 \mathrm{~g}$, $72.2 \mathrm{mmol}$ ) portionwise, and then the mixture was stirred at the same temperature for $1 \mathrm{~h}$. After addition of water and AcOEt $(300 \mathrm{ml})$, the mixture was filtrated. The two layers of the filtrate were separated, and the organic layer was dried over $\mathrm{Na}_{2} \mathrm{SO}_{4}$, and evaporated under reduced pressure. To a solution of the residue in $\mathrm{CH}_{2} \mathrm{Cl}_{2}(540 \mathrm{ml})$ was added activated $\mathrm{MnO}_{2}$ $(43.9 \mathrm{~g}, 505 \mathrm{mmol})$. After stirring at room temperature for $15 \mathrm{~h}$, activated $\mathrm{MnO}_{2}(10.0 \mathrm{~g}, 115 \mathrm{mmol})$ was added, and stirred for $6 \mathrm{~h}$. The mixture was filtrated, and the filtrate was evaporated under reduced pressure. The residue was purified by column chromatography (AcOEt: $n$-hexane $=1: 1$ ) to give $\mathbf{1 4}$ as a crystalline solid $(7.78 \mathrm{~g}, 62 \%$ yield $) .{ }^{1} \mathrm{H}-\mathrm{NMR}\left(\mathrm{CDCl}_{3}\right) \delta: 2.43(3 \mathrm{H}, \mathrm{s})$,
$2.54(3 \mathrm{H}, \mathrm{s}), 6.81(1 \mathrm{H}, \mathrm{s}), 7.06(1 \mathrm{H}, \mathrm{s}), 7.25(1 \mathrm{H}, \mathrm{s}), 9.15(1 \mathrm{H}, \mathrm{s}), 9.78(1 \mathrm{H}, \mathrm{s})$.

1-Acetyl-2-butyl-4,6-dimethylindoline (15): To a suspension of allyltriphenylphosphonium bromide $(25.0 \mathrm{~g}, 65.3 \mathrm{mmol})$ in tetrahydrofuran (THF) $(200 \mathrm{ml})$ was added $1.6 \mathrm{M} n$-BuLi in hexane $(65 \mathrm{ml}, 65 \mathrm{mmol})$ dropwise below $10{ }^{\circ} \mathrm{C}$. The reaction mixture was stirred at the same temperature for $20 \mathrm{~min}$. To the mixture was added $14(5.66 \mathrm{~g}, 32.7 \mathrm{mmol})$ in THF $(50 \mathrm{ml})$ at the same temperature. After stirring for $20 \mathrm{~min}$, water was added, and the mixture was extracted with AcOEt. The organic layer was washed with brine, dried over $\mathrm{Na}_{2} \mathrm{SO}_{4}$, and evaporated under reduced pressure. A solution of the residue in $\mathrm{MeOH}(400 \mathrm{ml})$ was hydrogenated at $0.4 \mathrm{MPa}$ in the presence of $10 \% \mathrm{Pd}-\mathrm{C}(2.70 \mathrm{~g})$ at $35^{\circ} \mathrm{C}$ for $16 \mathrm{~h}$. After removal of the catalyst by filtration, the filtrate was evaporated under reduced pressure. The residue was purified by column chromatography (AcOEt $: n$-hexane $=1: 3$ ). To a solution of the product in $\mathrm{AcOH}(38 \mathrm{ml})$ was added $\mathrm{NaBH}_{3} \mathrm{CN}$ (2.64 g, $37.8 \mathrm{mmol}$ ) portionwise at $10^{\circ} \mathrm{C}$, and then the mixture was stirred for $30 \mathrm{~min}$ at the same temperature. After addition of $\mathrm{NaOH}$ aqueous solution $\left(22 \mathrm{~g} / 72 \mathrm{ml}\right.$ ) at below $20^{\circ} \mathrm{C}$, the mixture was extracted with AcOEt. The organic layer was washed with saturated $\mathrm{NaHCO}_{3}$ solution and brine, dried over $\mathrm{Na}_{2} \mathrm{SO}_{4}$, and evaporated under reduced pressure. To a solution of the residue in $\mathrm{CHCl}_{3}(39 \mathrm{ml})$ were added $\mathrm{Ac}_{2} \mathrm{O}(2.7 \mathrm{ml}, 29 \mathrm{mmol})$, and $\mathrm{Et}_{3} \mathrm{~N}$ $(4.0 \mathrm{ml}, 29 \mathrm{mmol})$. After stirring at room temperature for $30 \mathrm{~min}$, the reaction mixture was washed with $10 \%$ citric acid solution, saturated $\mathrm{NaHCO}_{3}$ solution and brine, dried over $\mathrm{Na}_{2} \mathrm{SO}_{4}$, and evaporated under reduced pressure. The residue was purified by column chromatography (AcOEt: nhexane $=1: 2)$ to give $\mathbf{1 5}(3.48 \mathrm{~g}, 42 \%$ yield $) .{ }^{1} \mathrm{H}-\mathrm{NMR}\left(\mathrm{CDCl}_{3}\right) \delta: 0.80$ $1.00(3 \mathrm{H}, \mathrm{m}), 1.20-1.80(6 \mathrm{H}, \mathrm{m}), 2.20(3 \mathrm{H}, \mathrm{s}), 2.26(3 \mathrm{H}, \mathrm{s}), 2.31(3 \mathrm{H}, \mathrm{s})$, $2.50-2.74(1 \mathrm{H}, \mathrm{m}), 2.95-3.20(1 \mathrm{H}, \mathrm{m}), 4.20-4.40(0.7 \mathrm{H}, \mathrm{m}), 4.70-4.85$ $(0.3 \mathrm{H}, \mathrm{m}), 6.68(1 \mathrm{H}, \mathrm{s}), 6.74(0.3 \mathrm{H}, \mathrm{s}), 7.82(0.7 \mathrm{H}, \mathrm{s})$

$\mathrm{N}$-(2-Butyl-1,4,6-trimethyl-5-sulfamoylaminoindolin-7-yl)-2,2-dimethylpropanamide Hydrochloride (9d): A crystalline solid. mp $180-183^{\circ} \mathrm{C}$. IR (Nujol) $\mathrm{cm}^{-1}: 1672 .{ }^{1} \mathrm{H}-\mathrm{NMR}$ (DMSO- $\left.d_{6}\right) \delta: 0.85-0.95(3 \mathrm{H}, \mathrm{m}), 1.26(9 \mathrm{H}$, s), $1.30-1.40(4 \mathrm{H}, \mathrm{m}), 1.50-1.65(1 \mathrm{H}, \mathrm{m}), 1.85-2.00(1 \mathrm{H}, \mathrm{m}), 2.10(3 \mathrm{H}$, s), $2.25(3 \mathrm{H}, \mathrm{s}), 2.70-2.90(1 \mathrm{H}, \mathrm{m}), 2.83(3 \mathrm{H}, \mathrm{s}), 3.27(1 \mathrm{H}, \mathrm{dd}, J=15.6$, $7.1 \mathrm{~Hz}), 3.40-4.00(1 \mathrm{H}, \mathrm{m}), 6.40-7.20(2 \mathrm{H}, \mathrm{br}), 8.44(1 \mathrm{H}, \mathrm{s}), 9.24(1 \mathrm{H}, \mathrm{s})$. MS m/z: $409[\mathrm{M}-\mathrm{H}]^{-}$. Anal. Calcd for $\mathrm{C}_{20} \mathrm{H}_{34} \mathrm{~N}_{4} \mathrm{O}{ }_{3} \mathrm{~S} \cdot \mathrm{HCl} \cdot 0.7 \mathrm{H}_{2} \mathrm{O}: \mathrm{C}$, 52.26; H, 7.98; N, 12.19; Cl, 7.71. Found: C, 52.02; H, 7.60; N, 12.07; Cl, 7.59 .

Procedure for the Synthesis of 18a Compound 18a was synthesized from 13 via 19, 20, and 22a. Compound 20 was converted to 22a according to the procedure for 1a. Compound $\mathbf{2 0}$ was prepared as follows:

2-Acetoxymethyl-1-acetyl-4,6-dimethylindoline (19): To a suspension of $\mathrm{LiAlH}_{4}(2.10 \mathrm{~g}, 55.3 \mathrm{mmol})$ in $\mathrm{Et}_{2} \mathrm{O}(160 \mathrm{ml})$ in an ice bath was added 13 $(8.0 \mathrm{~g}, 37 \mathrm{mmol})$ portionwise, and then the mixture was stirred at the same temperature for $1 \mathrm{~h}$. After addition of water and AcOEt $(300 \mathrm{ml})$, the mixture was filtrated. The two layers of the filtrate were separated, and the organic layer was dried over $\mathrm{Na}_{2} \mathrm{SO}_{4}$, and evaporated under reduced pressure to give 2-hydroxymethyl-4,6-dimethylindole (36) as a crystalline solid. To a solution of 36 in $\mathrm{AcOH}(60 \mathrm{ml})$ was added $\mathrm{NaBH}_{3} \mathrm{CN}(5.14 \mathrm{~g}, 73.6 \mathrm{mmol})$ portionwise at $10^{\circ} \mathrm{C}$, and then the mixture was stirred for $30 \mathrm{~min}$ at the same temperature. After addition of $\mathrm{NaOH}$ aqueous solution $(40 \mathrm{~g} / 140 \mathrm{ml})$ below $20^{\circ} \mathrm{C}$, the mixture was extracted with AcOEt. The organic layer was washed with saturated $\mathrm{NaHCO}_{3}$ solution and brine, dried over $\mathrm{Na}_{2} \mathrm{SO}_{4}$, and evaporated under reduced pressure. To a solution of the residue in $\mathrm{CHCl}_{3}(70 \mathrm{ml})$ were added $\mathrm{Ac}_{2} \mathrm{O}(10.4 \mathrm{ml}, 110 \mathrm{mmol})$, and $\mathrm{Et}_{3} \mathrm{~N}(15.4 \mathrm{ml}, 110 \mathrm{mmol})$. After stirring at room temperature for $16 \mathrm{~h}$, the reaction mixture was washed with $10 \%$ citric acid solution, saturated $\mathrm{NaHCO}_{3}$ solution and brine, dried over $\mathrm{Na}_{2} \mathrm{SO}_{4}$, and evaporated under reduced pressure. The crystalline residue was rinsed with $i$ - $\mathrm{Pr}_{2} \mathrm{O}$ to obtain $19\left(7.43 \mathrm{~g}, 77 \%\right.$ yield). ${ }^{1} \mathrm{H}-\mathrm{NMR}\left(\mathrm{CDCl}_{3}\right) \delta$ : $2.00(3 \mathrm{H}, \mathrm{s}), 2.19(3 \mathrm{H}, \mathrm{s}), 2.31(3 \mathrm{H}, \mathrm{s}), 2.36(3 \mathrm{H}, \mathrm{s}), 2.70(1 \mathrm{H}, \mathrm{d}$ $J=16.0 \mathrm{~Hz}), 3.15(1 \mathrm{H}, \mathrm{dd}, J=16.0,8.6 \mathrm{~Hz}), 3.80-4.30(2 \mathrm{H}, \mathrm{m}), 4.50-5.20$ $(1 \mathrm{H}, \mathrm{m}), 6.69(1 \mathrm{H}, \mathrm{s}), 7.40-8.00(1 \mathrm{H}, \mathrm{br})$.

1-Acetyl-2-hydroxymethyl-4,6-dimethylindoline (37): To a solution of 19 $(17.4 \mathrm{~g}, 66.6 \mathrm{mmol})$ in $\mathrm{MeOH}(175 \mathrm{ml})$ in an ice bath was added $1.0 \mathrm{M} \mathrm{LiOH}$ aqueous solution $(80 \mathrm{ml}, 80 \mathrm{mmol})$, and then the mixture was stirred at the same temperature for $0.5 \mathrm{~h}$. After addition of $5 \%$ citric acid solution $(100 \mathrm{ml})$, the solvent was removed under reduced pressure. The precipitate formed was collected by filtration to obtain $\mathbf{3 7}$ as a crystalline solid (14.0 g, $96 \%$ yield). ${ }^{1} \mathrm{H}-\mathrm{NMR}\left(\mathrm{CDCl}_{3}\right) \delta: 1.50-2.20(1 \mathrm{H}, \mathrm{br}), 2.19(3 \mathrm{H}, \mathrm{s}), 2.31$ $(3 \mathrm{H}, \mathrm{s}), 2.40(3 \mathrm{H}, \mathrm{s}), 2.30-2.80(1 \mathrm{H}, \mathrm{m}), 3.00-3.40(1 \mathrm{H}, \mathrm{m}), 3.65(2 \mathrm{H}, \mathrm{d}$, $J=6.4 \mathrm{~Hz}), 4.50-5.20(1 \mathrm{H}, \mathrm{m}), 6.20-8.00(2 \mathrm{H}, \mathrm{m})$

1-Acetyl-2-methoxymethyl-4,6-dimethylindoline (20): To a solution of $\mathbf{3 7}$ $(8.34 \mathrm{~g}, 38.0 \mathrm{mmol})$ in DMF $(83 \mathrm{ml})$ in an ice bath was added $60 \%$ suspension of $\mathrm{NaH}$ in mineral oil $(1.37 \mathrm{~g}, 34 \mathrm{mmol})$. After stirring for $10 \mathrm{~min}$ at the same temperature, MeI $(11.8 \mathrm{ml}, 190 \mathrm{mmol})$ was added, and stirred for $1.5 \mathrm{~h}$ 
at $80^{\circ} \mathrm{C}$. After addition of $5 \%$ citric acid solution $(500 \mathrm{ml})$, the mixture was extracted with AcOEt. The organic layer was washed with saturated $\mathrm{NaHCO}_{3}$ solution and brine, dried over $\mathrm{Na}_{2} \mathrm{SO}_{4}$, and evaporated under reduced pressure. The residue was purified by column chromatography (AcOEt: $n$-hexane $=2: 1$ ) to give $\mathbf{2 0}$ as a crystalline solid $(3.95 \mathrm{~g}, 45 \%$ yield). ${ }^{1} \mathrm{H}-\mathrm{NMR}\left(\mathrm{CDCl}_{3}\right) \delta: 2.20(3 \mathrm{H}, \mathrm{s}), 2.31(6 \mathrm{H}, \mathrm{s}), 2.70-2.90(1 \mathrm{H}, \mathrm{m})$ $3.00-3.20(1 \mathrm{H}, \mathrm{m}), 3.25-3.65(2 \mathrm{H}, \mathrm{m}), 3.34(3 \mathrm{H}, \mathrm{s}), 4.54-4.98(1 \mathrm{H}, \mathrm{m})$, $6.69(1 \mathrm{H}, \mathrm{s}), 6.60-6.90(0.5 \mathrm{H}, \mathrm{br}), 7.70-7.90(0.5 \mathrm{H}, \mathrm{br})$.

$\mathrm{N}$-(2-Methoxymethyl-4,6-dimethyl-1-propyl-5-sulfamoylaminoindolin-7yl)-2,2-dimethylpropanamide Hydrochloride (18a): A crystalline solid. mp $170-173{ }^{\circ} \mathrm{C}$. IR (Nujol) $\mathrm{cm}^{-1}: 1649 .{ }^{1} \mathrm{H}-\mathrm{NMR}$ (DMSO- $\left.d_{6}\right) \delta: 0.80(3 \mathrm{H}, \mathrm{t}$, $J=7.3 \mathrm{~Hz}), 1.26(9 \mathrm{H}, \mathrm{s}), 1.40-1.70(2 \mathrm{H}, \mathrm{m}), 2.09(3 \mathrm{H}, \mathrm{s}), 2.20(3 \mathrm{H}, \mathrm{s})$, $2.60-2.80(1 \mathrm{H}, \mathrm{m}), 2.95-3.05(1 \mathrm{H}, \mathrm{m}), 3.20-3.35(5 \mathrm{H}, \mathrm{m}), 3.40-4.50$ $(6 \mathrm{H}, \mathrm{m}), 8.20-8.50(1 \mathrm{H}, \mathrm{br}), 9.00-9.40(1 \mathrm{H}, \mathrm{br}) . \mathrm{MS} m / z: 427[\mathrm{M}+\mathrm{H}]^{+}$ Anal. Calcd for $\mathrm{C}_{20} \mathrm{H}_{34} \mathrm{~N}_{4} \mathrm{O}_{4} \mathrm{~S} \cdot \mathrm{HCl} \cdot 0.5 \mathrm{H}_{2} \mathrm{O}: \mathrm{C}, 50.89 ; \mathrm{H}, 7.69 ; \mathrm{N}, 11.87 ; \mathrm{Cl}$, 7.51. Found: C, 50.63; H, 7.49; N, 11.62; Cl, 7.52.

Procedure for the Synthesis of $\mathbf{1 8 b}$ Compound $\mathbf{1 8 b}$ was synthesized from 19 according to the procedure for 18a. EtI was used instead of MeI.

$\mathrm{N}$-(2-Ethoxymethyl-4,6-dimethyl-1-propyl-5-sulfamoylaminoindolin-7yl)-2,2-dimethylpropanamide Hydrochloride (18b): A crystalline solid. mp $177-180{ }^{\circ} \mathrm{C}$. IR (Nujol) $\mathrm{cm}^{-1}: 1651 .{ }^{1} \mathrm{H}-\mathrm{NMR}\left(\mathrm{CDCl}_{3}\right) \delta: 0.82(3 \mathrm{H}, \mathrm{t}$, $J=7.3 \mathrm{~Hz}), 1.14(3 \mathrm{H}, \mathrm{t}, J=7.1 \mathrm{~Hz}), 1.26(9 \mathrm{H}, \mathrm{s}), 1.49-1.66(2 \mathrm{H}, \mathrm{m}), 2.12$ $(3 \mathrm{H}, \mathrm{s}), 2.21(3 \mathrm{H}, \mathrm{s}), 2.63-2.79(1 \mathrm{H}, \mathrm{m}), 2.95-3.06(1 \mathrm{H}, \mathrm{m}), 3.19-3.36$ $(2 \mathrm{H}, \mathrm{m}), 3.46-3.54(4 \mathrm{H}, \mathrm{m}), 3.60-4.35(1 \mathrm{H}, \mathrm{m}), 6.50-6.98(2 \mathrm{H}, \mathrm{br})$ $8.20-8.50\left(1 \mathrm{H}\right.$, br), $9.02-9.50\left(1 \mathrm{H}\right.$, br). MS m/z: $441[\mathrm{M}+\mathrm{H}]^{+}$. Anal. Calcd for $\mathrm{C}_{21} \mathrm{H}_{37} \mathrm{~N}_{4} \mathrm{O}_{4} \mathrm{~S} \cdot \mathrm{HCl} \cdot 0.2 \mathrm{H}_{2} \mathrm{O}: \mathrm{C}, 52.37 ; \mathrm{H}, 8.04 ; \mathrm{N}, 11.63 ; \mathrm{Cl}, 7.36$. Found: C, 52.23; H, 7.80; N, 11.66; Cl, 7.59.

Procedure for the Synthesis of 18c and 18d Compound 18c and 18d were synthesized from 19 via $\mathbf{2 3}$. Compound 23 was prepared according to the procedure for 9a. The hydroxymethyl moiety of $\mathbf{2 3}$ was converted to thioether moiety in a similar manner to that described in the procedure for $\mathbf{1} \mathbf{j}$ and $1 \mathbf{k}$.

$N$-(2-Hydroxymethyl-4,6-dimethyl-5-nitro-1-propylindolin-7-yl)-2,2-dimethylpropanamide (23): A crystalline solid. ${ }^{1} \mathrm{H}-\mathrm{NMR}\left(\mathrm{CDCl}_{3}\right) \delta: 0.85(3 \mathrm{H}$, $\mathrm{t}, J=7.3 \mathrm{~Hz}), 1.35(9 \mathrm{H}, \mathrm{s}), 1.40-1.55(2 \mathrm{H}, \mathrm{m}), 2.07(3 \mathrm{H}, \mathrm{s}), 2.12(3 \mathrm{H}, \mathrm{s})$, $2.76(1 \mathrm{H}, \mathrm{d}, J=16.1,4.4 \mathrm{~Hz}), 2.85-3.00(2 \mathrm{H}, \mathrm{m}), 3.10-3.30(2 \mathrm{H}, \mathrm{m})$, $3.40-3.50(1 \mathrm{H}, \mathrm{m}), 3.70-3.90(2 \mathrm{H}, \mathrm{m}), 6.94(1 \mathrm{H}, \mathrm{s})$.

$\mathrm{N}$-(4,6-Dimethyl-2-methylthiomethyl-1-propyl-5-sulfamoylaminoindolin7-yl)-2,2-dimethylpropanamide Hydrochloride (18c): A crystalline solid. mp $158-161{ }^{\circ} \mathrm{C}$. IR (Nujol) $\mathrm{cm}^{-1}: 1657 .{ }^{1} \mathrm{H}-\mathrm{NMR}$ (DMSO- $\left.d_{6}\right) \delta: 0.81(3 \mathrm{H}, \mathrm{t}$, $J=7.3 \mathrm{~Hz}), 1.26(9 \mathrm{H}, \mathrm{s}), 1.45-1.70(2 \mathrm{H}, \mathrm{m}), 2.01(3 \mathrm{H}, \mathrm{s}), 2.08(3 \mathrm{H}, \mathrm{s}), 2.14$ $(3 \mathrm{H}, \mathrm{s}), 2.57(1 \mathrm{H}, \mathrm{dd}, J=13.5,8.7 \mathrm{~Hz}), 2.75-3.05(2 \mathrm{H}, \mathrm{m}), 3.20-3.35$ $(2 \mathrm{H}, \mathrm{m}), 3.90-4.20(2 \mathrm{H}, \mathrm{m}), 5.80-7.40(2 \mathrm{H}, \mathrm{br}), 8.20-8.40(1 \mathrm{H}, \mathrm{br})$, $9.00-9.20\left(1 \mathrm{H}\right.$, br). MS m/z: $443[\mathrm{M}+\mathrm{H}]^{+}$. Anal. Calcd for $\mathrm{C}_{20} \mathrm{H}_{34} \mathrm{~N}_{4} \mathrm{O}_{3} \mathrm{~S}_{2}$. $\mathrm{HCl} \cdot 0.6 \mathrm{H}_{2} \mathrm{O}$ : C, 49.03; H, 7.45; N, 11.44; Cl, 7.24. Found: C, 48.78; H, 7.12; $\mathrm{N}, 11.42 ; \mathrm{Cl}, 7.56$.

$\mathrm{N}$-(2-Ethylthiomethyl-4,6-dimethyl-1-propyl-5-sulfamoylaminoindolin-7yl)-2,2-dimethylpropanamide Hydrochloride (18d): A crystalline solid. mp $155-159^{\circ} \mathrm{C}$. IR (Nujol) $\mathrm{cm}^{-1}: 1651 .{ }^{1} \mathrm{H}-\mathrm{NMR}$ (DMSO- $\left.d_{6}\right) \delta: 0.83(3 \mathrm{H}, \mathrm{t}$, $J=7.2 \mathrm{~Hz}), 1.20(3 \mathrm{H}, \mathrm{t}, J=7.3 \mathrm{~Hz}), 1.25(9 \mathrm{H}, \mathrm{s}), 1.40-1.70(2 \mathrm{H}, \mathrm{m}), 2.08$ $(3 \mathrm{H}, \mathrm{s}), 2.21(3 \mathrm{H}, \mathrm{s}), 2.50-3.10(6 \mathrm{H}, \mathrm{m}), 3.20-4.40(4 \mathrm{H}, \mathrm{m}), 6.50-7.50$ $(2 \mathrm{H}, \mathrm{br}), 8.30(1 \mathrm{H}, \mathrm{s}), 9.08(1 \mathrm{H}, \mathrm{s})$. MS $m / z: 457[\mathrm{M}+\mathrm{H}]^{+}$. Anal. Calcd for $\mathrm{C}_{21} \mathrm{H}_{36} \mathrm{~N}_{4} \mathrm{O}_{3} \mathrm{~S}_{2} \cdot \mathrm{HCl} \cdot 0.4 \mathrm{H}_{2} \mathrm{O}: \mathrm{C}, 50.41 ; \mathrm{H}, 7.61 ; \mathrm{N}, 11.20 ; \mathrm{Cl}, 7.09$. Found: C, 50.37; H, 7.54; N, 11.19; Cl, 7.21.

Procedure for the Synthesis of $\mathbf{2 4}$ Compound $\mathbf{2 4}$ was synthesized from $\mathbf{2 5}$ via 26. Conversion of $\mathbf{2 6}$ to $\mathbf{2 4}$ was accomplished according the procedure for 9a. Compound $\mathbf{2 6}$ was obtained as follows:

2-(4,6-Dimethylindol-3-yl)ethanol (38): To a solution of 4,6-dimethylindole (25) (26.0 g, $179 \mathrm{mmol})$ in $\mathrm{Et}_{2} \mathrm{O}(260 \mathrm{ml})$ in an ice bath was added oxalyl chloride $(30.6 \mathrm{ml}, 322 \mathrm{mmol})$. After stirring for $4 \mathrm{~h}$ at room temperature, the reaction mixture was evaporated under reduced pressure. A solution of the residue in EtOH $(200 \mathrm{ml})$ was stirred for $1 \mathrm{~h}$ at room temperature, and then the solvent was evaporated under reduced pressure. After dilution with AcOEt, the solution was washed with water, brine, dried over $\mathrm{Na}_{2} \mathrm{SO}_{4}$, and evaporated under reduced pressure. The residue was purified by column chromatography to give a crystalline residue. The residue was rinsed with $\mathrm{Et}_{2} \mathrm{O}$ to give ethyl (4,6-dimethylindol-3-yl)oxoacetate (39) as a crystalline solid $(21.2 \mathrm{~g}, 54 \%$ yield $)$. To a suspension of $\mathrm{LiAlH}_{4}(9.36 \mathrm{~g}, 247 \mathrm{mmol})$ in THF $(200 \mathrm{ml})$ was added the compound $39(20.2 \mathrm{~g}, 82.4 \mathrm{mmol})$ at room temperature. The reaction mixture was refluxed for $1 \mathrm{~h}$, and then water was added. After removal of insoluble material by filtration, the organic layer was separated, dried over $\mathrm{Na}_{2} \mathrm{SO}_{4}$, and evaporated under reduced pressure to give 38 as a crystalline solid $(15.8 \mathrm{~g}, 100 \%$ yield $) .{ }^{1} \mathrm{H}-\mathrm{NMR}\left(\mathrm{CDCl}_{3}\right) \delta: 2.39$ $(3 \mathrm{H}, \mathrm{s}), 2.63(3 \mathrm{H}, \mathrm{s}), 3.13(2 \mathrm{H}, \mathrm{t}, J=7.0 \mathrm{~Hz}), 3.86(2 \mathrm{H}, \mathrm{t}, J=7.0 \mathrm{~Hz}), 6.69$
$(1 \mathrm{H}, \mathrm{s}), 6.91(1 \mathrm{H}, \mathrm{s}), 6.92(1 \mathrm{H}, \mathrm{s}), 7.90(1 \mathrm{H}, \mathrm{s})$.

2-(4,6-Dimethylindolin-3-yl)ethanol (40): To a solution of 38 (16.5 g, $87.2 \mathrm{mmol})$ in $\mathrm{AcOH}(83 \mathrm{ml})$ was added $\mathrm{NaBH}_{3} \mathrm{CN}(10.7 \mathrm{~g}, 170 \mathrm{mmol})$ at $10^{\circ} \mathrm{C}$, and the mixture was stirred for $0.5 \mathrm{~h}$ at the same temperature. After addition of $\mathrm{NaOH}$ aqueous solution $(60 \mathrm{~g} / 200 \mathrm{ml})$ dropwise below $40^{\circ} \mathrm{C}$, the mixture was extracted with AcOEt. The organic layer was washed with water, saturated $\mathrm{NaHCO}_{3}$ solution, brine, dried over $\mathrm{Na}_{2} \mathrm{SO}_{4}$, and evaporated under reduced pressure to give $\mathbf{4 0}(16.3 \mathrm{~g}, 98 \%$ yield $)$ as a crystalline solid. ${ }^{1} \mathrm{H}-\mathrm{NMR}\left(\mathrm{CDCl}_{3}\right) \delta: 1.73-1.83(1 \mathrm{H}, \mathrm{m}), 1.85-1.94(1 \mathrm{H}, \mathrm{m}), 2.22(3 \mathrm{H}, \mathrm{s})$, $2.23(3 \mathrm{H}, \mathrm{s}), 3.30-3.60(6 \mathrm{H}, \mathrm{m}), 6.33(1 \mathrm{H}, \mathrm{s}), 6.37(1 \mathrm{H}, \mathrm{s})$.

3-(2-Methoxyethyl)-4,6-dimethylindoline (41): To a solution of 40 (16.3 g, $85.3 \mathrm{mmol})$ in THF $(160 \mathrm{ml})$ was added $\mathrm{Boc}_{2} \mathrm{O}(23.3 \mathrm{~g}, 107 \mathrm{mmol})$, and the reaction mixture was stirred for $2 \mathrm{~h}$ at room temperature. After evaporation under reduced pressure, the residue was purified by column chromatography (AcOEt: $n$-hexane =1:3) to give tert-butyl 3-(2-hydroxyethyl)-4,6-dimethylindoline-1-carboxylate (42) as an oil $(22.1 \mathrm{~g}, 89 \%$ yield). To a solution of $42(22.1 \mathrm{~g}, 75.8 \mathrm{mmol})$ in DMF $(110 \mathrm{ml})$ in an ice bath were added methyl iodide $(9.6 \mathrm{ml}, 0.15 \mathrm{~mol})$ and $60 \%$ suspension of $\mathrm{NaH}$ in mineral oil $(3.98 \mathrm{~g}, 99.5 \mathrm{mmol})$, and the mixture was stirred for $1 \mathrm{~h}$ at the same temperature. After addition of 5\% citric acid solution, the mixture was extracted with AcOEt. The organic layer was washed with water, saturated $\mathrm{NaHCO}_{3}$ solution, brine, dried over $\mathrm{Na}_{2} \mathrm{SO}_{4}$, and evaporated under reduced pressure to give tert-butyl 3-(2-methoxyethyl)-4,6-dimethylindoline-1-carboxylate (43) as an oil $(24.1 \mathrm{~g})$. To a solution of $43(24.0 \mathrm{~g}, 78.6 \mathrm{mmol})$ in $\mathrm{HCO}_{2} \mathrm{H}(72 \mathrm{ml})$ in an ice bath was added $8.7 \mathrm{M} \mathrm{HCl}$ in $i$-PrOH $(29 \mathrm{ml}, 0.25 \mathrm{~mol})$. The mixture was stirred for $15 \mathrm{~min}$ at the same temperature. After addition of water, the mixture was extracted with AcOEt. The organic layer was washed with saturated $\mathrm{NaHCO}_{3}$ solution, brine, dried over $\mathrm{Na}_{2} \mathrm{SO}_{4}$, and evaporated under reduced pressure to give $\mathbf{4 1}$ as an oil (15.6 g, 97\% yield). ${ }^{1} \mathrm{H}-\mathrm{NMR}\left(\mathrm{CDCl}_{3}\right) \delta$ : $1.73-1.94(2 \mathrm{H}, \mathrm{m}), 2.22(3 \mathrm{H}, \mathrm{s}), 2.23(3 \mathrm{H}, \mathrm{s}), 3.30-3.59(8 \mathrm{H}, \mathrm{m}), 6.33$ $(1 \mathrm{H}, \mathrm{s}), 6.37(1 \mathrm{H}, \mathrm{s})$.

1-Acetyl-3-(2-methoxyethyl)-4,6-dimethylindoline (26): To a solution of $41(15.5 \mathrm{~g}, 75.5 \mathrm{mmol})$ in $\mathrm{CHCl}_{3}(155 \mathrm{ml})$ in an ice bath were added $\mathrm{Ac}_{2} \mathrm{O}$ $(10.7 \mathrm{ml}, 113 \mathrm{mmol})$ and $\mathrm{Et}_{3} \mathrm{~N}(15.8 \mathrm{ml}, 113 \mathrm{mmol})$. After stirring for $1 \mathrm{~h}$ at room temperature, the mixture was washed with $5 \%$ citric acid solution, saturated $\mathrm{NaHCO}_{3}$ solution, brine, dried over $\mathrm{Na}_{2} \mathrm{SO}_{4}$, and evaporated under reduced pressure. The residue was purified by column chromatography (AcOEt: $n$-hexane $=1: 2$ ) to give $\mathbf{2 6}$ as a crystalline solid $(19.7 \mathrm{~g}, 100 \%$ yield). ${ }^{1} \mathrm{H}-\mathrm{NMR}\left(\mathrm{CDCl}_{3}\right) \delta: 1.66-1.74(1 \mathrm{H}, \mathrm{m}), 1.82-1.90(1 \mathrm{H}, \mathrm{m}), 2.22$ $(3 \mathrm{H}, \mathrm{s}), 2.25(3 \mathrm{H}, \mathrm{s}), 2.34(3 \mathrm{H}, \mathrm{s}), 3.32(3 \mathrm{H}, \mathrm{s}), 3.36-3.44(3 \mathrm{H}, \mathrm{m}), 3.85-$ $4.06(2 \mathrm{H}, \mathrm{m}), 6.68(1 \mathrm{H}, \mathrm{s}), 7.89(1 \mathrm{H}, \mathrm{s})$.

$N$-[3-(2-Methoxyethyl)-4,6-dimethyl-1-propyl-5-sulfamoylaminoindolin7-yl)-2,2-dimethylpropanamide Hydrochloride (24): A crystalline solid. mp $171-174{ }^{\circ} \mathrm{C}$. IR (Nujol) $\mathrm{cm}^{-1}: 1672 .{ }^{1} \mathrm{H}-\mathrm{NMR}$ (DMSO-d $) \delta: 0.87(3 \mathrm{H}, \mathrm{t}$, $J=7.3 \mathrm{~Hz}), 1.27(9 \mathrm{H}, \mathrm{s}), 1.57-1.78(2 \mathrm{H}, \mathrm{m}), 1.88-2.00(2 \mathrm{H}, \mathrm{m}), 2.12(3 \mathrm{H}$, s), $2.33(3 \mathrm{H}, \mathrm{s}), 3.02-3.12(1 \mathrm{H}, \mathrm{m}), 3.20-3.80(9 \mathrm{H}, \mathrm{m}), 6.60-7.10(2 \mathrm{H}$, br), $8.45(1 \mathrm{H}, \mathrm{s}), 9.16(1 \mathrm{H}, \mathrm{s})$. MS $m / z: 441[\mathrm{M}+\mathrm{H}]^{+}$. Anal. Calcd for $\mathrm{C}_{21} \mathrm{H}_{36} \mathrm{~N}_{4} \mathrm{O}_{4} \mathrm{~S} \cdot \mathrm{HCl} \cdot 0.2 \mathrm{H}_{2} \mathrm{O}: \mathrm{C}, 52.48 ; \mathrm{H}, 7.84 ; \mathrm{N}, 11.66 ; \mathrm{Cl}, 7.38$. Found: $\mathrm{C}$, 52.37; H, 7.82; N, 11.62; Cl, 7.48.

Partition Coefficient at $\mathbf{p H} \quad \mathbf{7 . 0} \log D_{7.0}$ values (logarithm of octanol-water partition coefficients at $\mathrm{pH}$ 7.0) were determined by HPLC methods. ${ }^{15)}$ Acetanilide, benzonitrile, benzene, bromobenzene, biphenyl and hexachlorobenzene, the $\log D_{7.0}$ values of which are known, were used as reference substances. Test compounds and reference substances were dissolved in acetonitrile containing $1 \%$ dimethylsulfoxide (DMSO) at $10 \mu \mathrm{g} / \mathrm{ml}$, and then $10 \mu \mathrm{l}$ of the solution was injected into the HPLC system. The HPLC equipment consisted of a pump (PU-980; JASCO, Tokyo, Japan), a UV detector (UV-970; JASCO), an autoinjector (AS-950; JASCO), and a Cosmosil 5C18-AR-II column $(5 \mu \mathrm{m}, 4.6 \mathrm{~mm} \times 150 \mathrm{~mm}$; Nacalai Tesque, Kyoto, Japan). Phosphate buffer ( $\mathrm{pH} 7.0)-\mathrm{MeOH}(8: 2)$ was used as the eluent. The capacity factors of test substances and reference substances were calculated from their retention time. The $\log D_{7.0}$ values of test compounds were calculated using these capacity factors and the reported $\log D_{7.0}$ values of reference substances.

Biological Evaluations of Compounds All experiments were conducted according to the guidelines for animal experiments of our institute and the Guidelines for Animal Experimentation approved by the Japanese Association of Laboratory Animal Science and the Japanese Pharmacological Society.

Plasma Protein Binding ratio (PBR): The plasma protein binding ratio was estimated by an ultracentrifugation method. ${ }^{16)}$ Test compounds were dissolved in rabbit plasma $(10 \mu \mathrm{g} / \mathrm{ml})$, which was isolated from blood taken from male Japanese white rabbits (JW rabbits, 6 months old; Japan SLC Inc., Hamamatsu, Japan). The concentration of the plasma was determined 
using the API 2000 QTRAP LC-MS/MS system (Applied Biosystems). The plasma was then separated into three layers by ultracentrifugation at $436000 \times \boldsymbol{g}$ for $150 \mathrm{~min}$ with a small ultracentrifuge (CS100GX; Hitachi Koki, Hitachinaka, Japan). The concentrations of the test compounds in the middle layer (protein-free fraction) were determined using the API 2000 QTRAP LC-MS/MS system. From the total and protein-free fraction concentrations, the protein binding ratio of the test compounds was calculated.

Plasma and Arterial Levels of Compounds after Oral Administration: Compound 1i and Pactimibe sulfate were suspended in 5\% arabic gum and administered orally at $10 \mathrm{mg} / \mathrm{kg}$ to male Sprague-Dawley (SD) rats (7 weeks old; Japan SLC Inc.), beagles (47, 60 months; NARC Co., Yamatake, Japan), and male JW rabbits (5-7 months; Japan SLC Inc.). Blood samples were drawn using a heparinized syringe from the jugular or ear vein at 0.25 , $0.5,1,2,3,5,8$, and $24 \mathrm{~h}$ after administration. Blood was centrifuged at $3000 \mathrm{rpm}$ for $10 \mathrm{~min}$ at room temperature. The concentrations of $\mathbf{1 i}$ and Pactimibe in the plasma were determined using HPLC. In another set of experiments, $1 \mathbf{i}(30 \mathrm{mg} / \mathrm{kg})$ and Pactimibe $(10 \mathrm{mg} / \mathrm{kg})$ were orally administered, blood was taken, and the atherosclerotic aorta was isolated after euthanasia by deep anesthesia. The concentrations of both compounds in the plasma and aorta were determined using HPLC, and the partition ratio from plasma to the aorta was calculated.

Esterified Cholesterol (EC) Accumulation in THP-1 Cell-Derived Macrophages: The effects of the test compounds on EC accumulation in THP-1 cells were determined during differentiation and foam cell formation. In order to cause the cells to differentiate into macrophages and to form foam cells, THP-1 cells were suspended in RPMI-1640 medium containing fetal bovine serum (FBS, 10\%) and phorbol 12-myristate 13-acetate (PMA, $200 \mathrm{~nm})$ with acetyl low density lipoprotein (LDL) $(400 \mu \mathrm{g}$ protein/ml), and then they were incubated at $4 \times 10^{5}$ cells/well in a humidified atmosphere of $95 \%$ air, $5 \% \mathrm{CO}_{2}$ at $37^{\circ} \mathrm{C}$ for $3 \mathrm{~d}$ in the presence or absence of the test compounds. Acetyl LDL was prepared from the serum of male KHC rabbits (6-8 months old; Japan Laboratory Animals, Inc., Tokyo, Japan). In another set of experiments, the effects of compound 1i and Pactimibe on EC accumulation by high-cholesterol serum (HCS) were investigated in the presence of bovine serum albumin (BSA). THP-1 cells were suspended in RPMI-1640 medium containing FBS $(10 \%)$ and PMA (200 nM), incubated at $4 \times 10^{5} \mathrm{cells} /$ well in a humidified atmosphere of $95 \%$ air, $5 \% \mathrm{CO}_{2}$ at $37^{\circ} \mathrm{C}$ for $3 \mathrm{~d}$, and then they were incubated in RPMI-1640 medium containing HCS $(3 \%)$ with or without BSA $(5 \%)$ in the presence or absence of the test compounds for a day. HCS was isolated from male JW rabbits ( $4-5$ months old; Japan SLC Inc.) fed a high cholesterol diet for 1 month. Cellular cholesterol was extracted by $n$-hexane $/ i-\operatorname{PrOH}(3: 2)$ and determined by enzymatic methods. EC content was calculated by subtracting the amount of free cholesterol from the total amount of cholesterol. Cellular protein was measured by Lowry's method.

In Vitro ACAT Activity: Male JW rabbits (2.5 kg, Japan SLC) were anesthetized with sodium pentobarbital $(30 \mathrm{mg} / \mathrm{kg}$, intravenously (i.v.)) and exsanguinated from the common carotid artery, and then the liver was isolated. Microsomes were prepared according to the method of Field and Mathur. ${ }^{17)}$ Briefly, each sample was homogenized in a buffered sucrose solution $\left(250 \mathrm{~mm}\right.$ sucrose, $5 \mathrm{~mm} \mathrm{~K}_{2} \mathrm{HPO}_{4} / \mathrm{KH}_{2} \mathrm{PO}_{4}, 1 \mathrm{~mm}$ ethylenediaminetetraacetic acid (EDTA), and $1 \mathrm{~mm}$ dithioerythritol, $\mathrm{pH}$ 7.4) using a Teflon-glass homogenizer. The homogenate was centrifuged at $12000 \times \boldsymbol{g}$ for $15 \mathrm{~min}$ at $4^{\circ} \mathrm{C}$. The resulting supernatant was centrifuged at $105000 \times \boldsymbol{g}$ for $30 \mathrm{~min}$ at $4{ }^{\circ} \mathrm{C}$. The microsomal fraction was used as the ACAT preparation. ACAT activity was determined according to the method described by Heider et al. ${ }^{18)}$ The microsomes were incubated in $154 \mathrm{~mm}$ phosphate buffer ( $\mathrm{pH} 7.4$ ) containing bovine serum albumin. Test compounds were applied and preincu- bated at $37^{\circ} \mathrm{C}$ for $5 \mathrm{~min}$, and then $30 \mathrm{nmol}$ of $\left[1-{ }^{14} \mathrm{C}\right]$ oleoyl-CoA (PerkinElmer, Waltham, MA, U.S.A.) was added. The reaction mixture was incubated at $37^{\circ} \mathrm{C}$ for $20 \mathrm{~min}$. Lipids were extracted with $\mathrm{CHCl}_{3} / \mathrm{MeOH}$ $(2: 1)$ and separated by thin-layer chromatography. The EC produced in microsomes treated with vehicle and test compounds were determined. $\mathrm{IC}_{50}$ values were calculated using data at the concentrations of test compounds in each experiment and the mean value was calculated for 2 experiments.

In Vitro Cholesterol Esterification in Atherosclerotic Aorta The aorta was isolated from $\mathrm{KHC}$ rabbits, and atherosclerotic areas were minced and then equally weighed out $200 \mathrm{mg}$ samples. These aortic samples were treated with compounds $1 \mathbf{i}$ and Pactimibe and incubated with ${ }^{14} \mathrm{C}$-oleic acid at $37{ }^{\circ} \mathrm{C}$ for $24 \mathrm{~h}$ in JW rabbit serum. Then, lipids were extracted with $\mathrm{CHCl}_{3} / \mathrm{MeOH}$ $(2: 1)$ and separated by TLC. The EC produced in the samples incubated with vehicle or test compounds was determined.

\section{References}

1) Kathawala F. G., Heider J. G., "Acyl CoA: Cholesterol Acyltransferase Inhibitors and Lipid-Lipoprotein Metabolism," ed. by Witiak D. T., Newman H. A. I., Feller D. R., Antilipidemic Drugs, Elsevier Science, Amsterdam, 1991, pp. 159-195.

2) Sliskovic D. R., White A. D., Trends Pharmacol. Sci., 12, 194-199 (1991).

3) Chang C., Dong R., Miyazaki A., Sakashita N., Zhang Y., Liu J., Guo M., Li B. L., Chang T. Y., Acta Biochim. Biophys. Sin., 38, 151-156 (2006).

4) Matsuda K., Med. Res. Rev., 14, 271-305 (1994).

5) Sliskovic D. R., Picard J. A., Krause B. R., Prog. Med. Chem., 39 , 121-171 (2002)

6) Roth B. D., Drug Discov. Today, 3, 19-25 (1998).

7) Takahashi K., Kasai M., Ohta M., Shoji Y., Kunishiro K., Kanda M. Kurahashi K., Shirahase H., J. Med. Chem., 51, 4823-4833 (2008).

8) Terasaka N., Miyazaki A., Kasanuki N., Ito K., Ubukata N., Koieyama T., Kitayama K., Tanimoto T., Maeda N., Inaba T., Atherosclerosis, 190, 239-247 (2007).

9) Kitayama K., Koga T., Maeda N., Inaba T., Fujioka T., Eur. J. Pharmacol., 539, 81-88 (2006)

10) Nissen S. E., Tuzcu E. M., Brewer H. B., Sipahi I., Nicholls S. J., Ganz P., Schoenhagen P., Waters D. D., Pepine C. J., Crowe T. D., Davidson M. H., Deanfield J. E., Wisniewski L. M., Hanyok J. J., Kassalow L. M., N. Engl. J. Med., 354, 1253-1263 (2006).

11) Kamiya S., Shirahase H., Yoshimi A., Nakamura S., Kanda M., Matsui H., Kasai M., Takahashi K., Kurahashi K., Chem. Pharm. Bull., 48, $817-827$ (2000).

12) Henn L., Hickey D. M. B., Moody C. J., Rees C. W., J. Chem. Soc. Perkin Trans. 1, 1984, 2189-2197 (1984).

13) Nakamura S., Kamiya S., Shirahase H., Kanda M., Yoshimi A., Tarumi T., Kurahashi K., Arzneim.-Forsch., 54, 102-108 (2004).

14) Nagarajan K., Talwalker P. K., Kulkarni C. L., Venkateswarlu A., Prabhu S. S., Nayak G. V., Indian J. Chem., Sect. B: Org. Chem. Incl. Med. Chem., 23, 1243-1257 (1984).

15) Masumoto K., Takeyasu A., Oizumi K., Kobayashi T., Yakugaku Zasshi, 115, 213-220 (1995).

16) Nakai D., Kumamoto K., Sakikawa C., Kosaka T., Tokui T., J. Pharm. Sci., 93, 847-854 (2004).

17) Field F. J., Mathur S. N., J. Lipid Res., 24, 409-417 (1983).

18) Heider J. G., Pickens C. E., Kelly L. A., J. Lipid Res., 24, 1127-1134 (1983). 